Article

\title{
Blue Carbon Cooperation in the Maritime Silk Road with Network Game Model and Simulation
}

\author{
Changping Zhao ${ }^{1}$, Xiaojiang Xu ${ }^{1}$, Yu Gong ${ }^{2, * \mathbb{D}}$, Houming Fan ${ }^{1}$ and Haojia Chen ${ }^{3}$ \\ 1 College of Shipping Economics and Management, Dalian Maritime University, Dalian 116026, China; \\ zhao0037@sina.com (C.Z.); m18342205102@163.com (X.X.); fhm468@dlmu.edu.cn (H.F.) \\ 2 Southampton Business School, University of Southampton, Southampton SO17 1BJ, UK \\ 3 WMG, University of Warwick, Coventry CV4 7AL, UK; haojia.chen@warwick.ac.uk \\ * Correspondence: y.gong@soton.ac.uk; Tel.: +44-(0)238-059-1834
}

Received: 24 March 2019; Accepted: 6 May 2019; Published: 14 May 2019

check for updates

\begin{abstract}
The blue carbon cooperation is a joint effort of the countries along the Maritime Silk Road (MSR) to utilize marine activities and organisms to absorb and store carbon dioxide in the atmosphere, an initiative that has great strategic value for coping with the most important environmental problems in the 21st century and promoting the building of a community with shared aspirations for mankind's future. This research combines the decision-making structure model with the reality of the blue carbon cooperation game of the MSR to make conditional assumptions and carry out model construction. It uses the simulation method to test the influencing factors such as decision-maker type, initial input cost, continuous input maintenance cost, rate of return, carbon tax rate and others. The results suggest that initial and continuous input costs, returns, and neighbor subsidies have positive impacts on blue carbon cooperation, while carbon tax rates and income discount rates have negative impacts on blue carbon cooperation. To promote blue carbon cooperation along the MSR, emphasis should be placed on the design of incentive and subsidy mechanisms, together with the appropriate punishment mechanisms.
\end{abstract}

Keywords: maritime silk road; blue carbon; cooperation network game model; simulation

\section{Introduction}

Global warming is one of the most important environmental problems facing humanity in the 21st century. Many countries around the world are working to resolve it through climate negotiations and the formulation of domestic environmental laws. The major achievement of the climate negotiations, the Paris Agreement, which establishes a model of cooperation between the nations of the alliance, came into effect at the end of 2016. Most of the countries and regions have focused their efforts on the control and reduction of greenhouse gas emissions, and some countries have been advanced in forest carbon sinks, while they paid little attention to the most efficient approach to help fix and store carbon-blue carbon.

Blue carbon refers to the processes, activities and mechanisms that utilize marine activities and organisms to absorb and store carbon dioxide in the atmosphere. Previous studies have shown that the most efficient blue carbon ecosystems are seagrass beds, mangroves, and salt marshes [1]; other results report that large seaweeds, shellfish and micro-organisms [2] also show outstanding performance in the fixation and storage of carbon. The carbon sequestration capacity of coastal blue carbon is far greater than that of the terrestrial carbon pool in per unit area [3]. However, due to the narrow pursuit of economic value, about one-third of mangroves, seagrasses and salt marshes have begun to degenerate or disappear due to reclamation, deforestation, coastal aquaculture, coastal 
land development, industrial production and climate change [4-7]. Thus, strengthening blue carbon protection on a global scale has become a vital and urgent initiative.

Promoting blue carbon protection mainly depends on cooperative development and common protection of the ocean. In recent years, China has been at the forefront of the world in blue carbon research. The theoretical framework of the marine microbial carbon pump (MCP) proposed by the team of Academician Jiao Nianzhi explains the source of the ocean's huge dissolved organic carbon pool (new blue carbon), which has received extensive attention and recognition from international counterparts [8], and has been featured on many covers of top publications such as Nature and Science. Using major MCP processes, a coupled physical-ecosystem model in the South China Sea (SCS) has been developed and the results suggest that the role of the MCP might become more significant under future climate change conditions [9]. The cost-and-benefit pricing model of the blue carbon sink in marine ranching has been constructed to help China build a perfect blue carbon sink exchange trading market [10]. Meanwhile, many countries and regions, including Partnerships in Environmental Management for the Seas of East Asia (PEMSEA) countries, recognize the importance of mangroves and try to build awareness and accelerate practical action on blue carbon by improving quantification of greenhouse emissions, measuring the significance of coastal blue carbon ecosystems across different policy frameworks and developing climate change vulnerability assessments, adaptation and resilience plans.

The Maritime Silk Road (MSR) can be an important bridge for economic and cultural exchanges between the East and the West, and the cooperation between countries is closely linked through trade along the road. The economic development of the MSR follows a trend of high at both ends and low in the middle: the economic development of East Asia and Europe enjoys strong momentum, while the economic growth of central Asia and the Middle East is relatively slow. Although the industrial division and cooperation along the MSR is immature, the ongoing development is highly complementary [11]. In view of the economic development pattern, by taking advantage of China's leading edge in blue carbon research, the blue carbon cooperation along the Silk Road can optimize the new pattern of Eurasian development space, so as to promote the sustainable economic development of the MSR.

One of the cooperation actions is that, in a recent report, around fifty countries-including the majority of East Asian countries-have started building deforestation and forest degradation implementation frameworks, with financial support from developed countries. These frameworks have habitat (mangroves) overlap with blue carbon interventions. Many countries, especially China, Malaysia and partially Vietnam, have formulated reduction targets related to the amount of $\mathrm{CO}_{2}$ emitted per unit of GDP, which included in the country's so-called nationally determined contribution. This report considered the economic and environmental issues associated with blue carbon in East Asia and is the most detailed blue carbon report so far. In addition, this report introduced the current blue carbon measurements and protection measures in East Asian countries, and proposed some practical steps to promote blue carbon intervention, including awareness building, knowledge sharing and exchange of best practices. These measures provide direction for domestic and international blue carbon protection, but the report did not emphasize the importance of international cooperation, let alone the specific implementation of international blue carbon cooperation [12].

Based on the initiative of the "Blue Carbon Cooperation Program along the 21st Century Maritime Silk Road" proposed by the Chinese government, Zhang et al. [13] summarized the driving force, realization and guarantee mechanism of the international blue carbon cooperation by reviewing China's blue carbon resources and maritime international cooperation on the MSR. The author believed that the development of blue carbon needs to form a consensus at various levels at home and abroad to seek common cooperation. By establishing the realization and guarantee mechanism of blue carbon cooperation, a path of blue carbon development can be opened under the framework of a cooperation mechanism to achieve the goal of joint development. Besides, the importance of technological and financial support has been mentioned many times in this article, which is in line with the knowledge 
sharing and blue economy mentioned in the East Asian Blue Carbon Report. Still, this article did not give a specific implementation plan.

This lack of an explicit consideration of the influencing factors and specific implementation on achieving blue carbon cooperation lead to the following research questions:

Q1. How to achieve the blue carbon international cooperation?

Q2. What is the impact of factors in the implementation process of blue carbon cooperation?

The answers to these questions provide a reference for blue carbon international cooperation and provide solutions for countries along the MSR to jointly address global climate change and environment issues.

In this research we propose a complex network with non-trivial topological features. Based on the complex network theory, a map of blue carbon corporation networks along the MSR is constructed, which can push development of sustainable marine environment by integrating coastal resources along the MSR. After that, this paper combines the decision-making structure type to establish and simulate a game model on the basis of network, and analyzes the influence of different factors on promoting the blue carbon cooperation among countries along the MSR, which aims to provide references and guidelines for the blue carbon cooperation countries along the road, accelerate the development of regional trade, and most importantly, promote the sustainable development of marine environment on the MSR to mitigate global warming problems. In contrast to former studies, our research established a game model of blue carbon cooperation and used simulation analysis to simulate this cooperation and observe the impact of the influencing factors.

The next part of the article provides a literature review on blue carbon. The third part constructs a complex network of blue carbon cooperation on the MSR and establishes a network game model based on the interpretation of the decision-making structure model and realistic conditions. In the fourth part, the simulation method is used to simulate the network game model of the MSR. The final section summarizes the conclusions of the simulation graphics and explores measures to promote blue carbon cooperation on the MSR in order to answer the research questions.

\section{Literature Review}

Blue carbon protection is scientifically credible. In the past 10 years, research on "blue carbon" has increased significantly due to the global environmental threats the world is facing. From the literature review, it is clear that scholars have focused on the scientific mechanism, technical development and application, and involved with the sustainable development of blue carbon. The principal economic, regulatory and political issues of blue carbon that emerge are discussed [14,15].

The most representative global achievement in blue carbon research is "Blue carbon: A UNEP rapid response assessment", a report jointly issued in 2009 by the United Nations Environment Programme (UNEP), Food and Agriculture Organization (FAO) of the United Nations, United Nations Educational, Scientific and Cultural Organization (UNESCO), and the Intergovernmental Oceanographic Commission [16]. The report elaborates on six aspects of carbon fixation, ocean and climate, functions and present situation of blue carbon, significance to human society, and ways of change.

In the scientific mechanism and technical research of blue carbon, Garrard [17] studied the effects of ocean acidification on carbon storage and integration in seaweed beds. Murdiyarso [18] believed that Indonesia has lost $40 \%$ of mangroves for aquaculture development over the past 30 years, resulting in annual emissions of 0.07 to $0.21 \mathrm{PgCO}_{2} \mathrm{e}\left(\mathrm{Pg}\right.$ is the unit of carbon storage, $1 \mathrm{Pg}=10^{15} \mathrm{~g}$ ). Duarte [19-21] studied the main functions of marine vegetation in the marine carbon cycle and assessed the carbon storage in marine vegetation sediments. Pendleton [22] estimated the amount of carbon dioxide released into the atmosphere when the blue carbon ecosystem degrades, and found that it yielded $\mathrm{CO}_{2}$ emissions of between 0.15 and 1.02 million tons per year. Sanders [23] postulated that if mangrove deforestation is curbed, global mangrove carbon stocks may increase by nearly $10 \%$ by 2115 due to increased tropical rainfall. Meanwhile, Li et al. [24] evaluated the dynamics of blue carbon storage in 
coastal wetlands under coastal reclamation in China, and found that more than 380,000 hectares of coastal wetlands were affected by reclamation between 1990 and 2015, which led to a release of ca. 20.7 $\mathrm{Tg}$ (ca. means circa/about, $1 \mathrm{Tg}=10^{12} \mathrm{~g}$ ) of blue carbon, accounting for $72.5 \%$ of total carbon loss.

In the management and cooperation research of blue carbon, Lovelock [25] proposed a framework for assessing the risk of carbon dioxide emissions caused by degraded soil, and from his findings constructed carbon value form. Laffoley [26] published book on coastal carbon sink management, and Vierros [27] pointed that the management and protection of blue carbon ecosystems could encourage collaboration between climate change and biodiversity practitioners on the national and international levels.

All the research results have proved that (i) the scientificity and feasibility of blue carbon protection, (ii) the necessity of strengthening the international cooperation of blue carbon protection, and (iii) the specified design path of the incentive and punishment mechanism of carbon sink, which provide a theoretical basis for exploring and analyzing the quantitative model of blue carbon international cooperation. However, the existing research has not focused on the design of the blue carbon cooperation model of the MSR, which is the major international transportation hub. The resulting construction of ports, the balanced development of the port network and the regional cooperation along the MSR can help to optimize routes, reduce energy consumption, promote regional trade, and achieve sustainable development goals [28].

Since $1980,20 \%$ of the world's mangroves have been destroyed, which greatly accelerates the deterioration of the climate. If the blue carbon with a combined area of only $2 \%$ to $6 \%$ of the tropical forest area is destroyed, the carbon emissions will be about $19 \%$ higher than the effects of deforestation [29-32]. According to a blue carbon report published by PEMSEA, East Asian countries, which the blue carbon ecosystems are heavily concentrated in, have the world's largest coastal carbon stocks and some of the most vulnerable coastal communities to the influences of climate change. All three blue carbon ecosystems-mangroves, tidal marshes and seagrass meadows-occur in East Asia. Tidal marshes occur primarily in China, Japan, North Korea and South Korea. It is speculated that less than 60,000 ha of tidal marsh remains across the region. Seagrasses are extensive but hard to assess accurately due to their subtidal location. Although there is a lack of data on seagrass distributions, several surveys are conducted to specific countries. For example, estimates of 3,000,000 ha of seagrass beds occur throughout Indonesia and all the Indonesian seagrasses contain 368.5 million metric tons of $\mathrm{CO}_{2}$ within the plants and soil. Mangroves are the dominant ecosystem type covering most of East Asia. Current status of mangrove ecosystem's distribution in East Asia, estimated carbon stocks and estimated emissions due to ecosystem loss are shown in Table 1. Among them, MFW and Biome (TEOW) refer to the Mangrove Forests of the World dataset and the Terrestrial Ecosystems of the World dataset respectively, which were mapped to assess the status of mangrove [12,33].

Table 1. The status of mangrove ecosystem in 2012.

\begin{tabular}{|c|c|c|c|c|c|c|c|c|c|c|}
\hline \multirow[t]{2}{*}{ Country } & \multicolumn{2}{|c|}{$\begin{array}{c}\text { Estimated } \\
\text { Mangrove Area in } \\
2000\end{array}$} & \multicolumn{2}{|c|}{$\begin{array}{c}\text { Estimated } \\
\text { Mangrove Area in } \\
2012\end{array}$} & \multicolumn{4}{|c|}{$\begin{array}{c}\text { Estimates of Mangrove Loss between } 2000 \\
\text { and } 2012\end{array}$} & \multicolumn{2}{|c|}{$\begin{array}{l}\text { Estimates of Carbon Stocks } \\
\text { in 2012(Hamilton } \\
\text { Mangrove and Soil Model) }\end{array}$} \\
\hline & MFW & Biome & MFW & Biome & MFW & Annually & Biome & Annually & MMt C & $\mathrm{MMt} \mathrm{CO}_{2} \mathrm{Eq}$. \\
\hline Indonesia & $2,407,313$ & $4,664,152$ & $2,332,429$ & $4,305,957$ & $3.11 \%$ & $0.26 \%$ & $7.68 \%$ & $0.64 \%$ & 1253.80 & 4597.30 \\
\hline Malaysia & 496,868 & 873,795 & 472,584 & 770,043 & $4.89 \%$ & $0.41 \%$ & $11.87 \%$ & $0.99 \%$ & 254.20 & 932.00 \\
\hline Philippines & 209,105 & 211,515 & 206,424 & 208,761 & $1.28 \%$ & $0.11 \%$ & $1.30 \%$ & $0.11 \%$ & 102.30 & 375.20 \\
\hline Thailand & 193,345 & 436,165 & 188,633 & 399,979 & $2.44 \%$ & $0.20 \%$ & $8.30 \%$ & $0.69 \%$ & 90.00 & 330.00 \\
\hline Viet Nam & 71,640 & 128,791 & 70,817 & 126,293 & $1.15 \%$ & $0.10 \%$ & $1.94 \%$ & $0.16 \%$ & 33.00 & 121.00 \\
\hline Cambodia & 33,839 & 75,339 & 32,322 & 65,375 & $4.48 \%$ & $0.37 \%$ & $13.23 \%$ & $1.10 \%$ & 15.10 & 55.40 \\
\hline China & 3223 & 3580 & 3155 & 3491 & $2.11 \%$ & $0.18 \%$ & $2.49 \%$ & $0.21 \%$ & 5.20 & 18.90 \\
\hline Brunei Darussalam & 10,423 & 14,652 & 10,341 & 14,345 & $0.79 \%$ & $0.07 \%$ & $2.10 \%$ & $0.17 \%$ & 0.30 & 1.30 \\
\hline Timor-Leste & 857 & 853 & 846 & 843 & $1.28 \%$ & $0.11 \%$ & $1.17 \%$ & $0.10 \%$ & 0.20 & 0.90 \\
\hline Japan & 792 & 803 & 786 & 797 & $0.76 \%$ & $0.06 \%$ & $0.75 \%$ & $0.06 \%$ & 0.10 & 0.40 \\
\hline Singapore & 167 & 167 & 167 & 165 & $0.00 \%$ & $0.00 \%$ & $1.20 \%$ & $0.10 \%$ & 0.07 & 0.20 \\
\hline Total & $3,427,572$ & $6,409,812$ & $3,318,504$ & $5,896,049$ & - & - & - & - & 1754.27 & 6432.6 \\
\hline
\end{tabular}

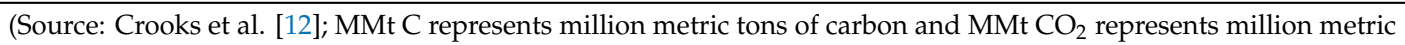
tons of carbon dioxide). 
Countries have been gradually raising the awareness of blue carbon. China, Vietnam, Thailand, the Philippines and Japan have been strong performers in early carbon emissions trading. The Philippines explicitly mentions the potential of blue carbon, and Vietnam highlights the need to protect, restore and improve coastal forests. Japan and Korea show their interest in forest carbon emissions projects [12]. While actions each country take within national borders to support coastal blue carbon ecosystems are efficient, the problem of climate change is a global issue that requires the active cooperation and joint efforts among all the countries.

It can be seen from the above literature that the current researches on blue carbon-related papers are mainly based on the measurement of blue carbon, and many papers have deduced the measures or paths for the development of blue carbon cooperation; blue carbon reports published by some organizations mainly use statistical methods to specifically explain and analyze the distribution of blue carbon ecosystems, the status of carbon sequestration and carbon storage, and international cooperation, additionally, have pointed out the future trends. Among them, blue carbon reports provide more information on blue carbon-related cooperation projects between different countries or regions. The blue carbon accounting rules, issued by the Intergovernmental Panel on Climate Change, recently was updated with a dedicated section to set a unified accounting standard for national reports on blue carbon emissions from mangroves, tidal marshes and seagrass meadows, which is conducive to the formation of blue carbon cooperation among countries. Besides, blue national appropriate mitigation actions (NAMAs), which were first introduced under the Bali Action Plan for developing countries to develop specific mitigation actions, are under preparation or implementation worldwide, including the NAMA for the sustainable development of Peatland in Indonesia [12]. All of these provide a cooperation basis for blue carbon. On the other hand, blue carbon cooperation is a joint effort of marine protection whereby all countries on the MSR can gain spillover effects and social benefits from the activities. Many pilot projects are ongoing all around the world, and their smooth progress can provide valuable experiences and references [14].

Although carbon stock, emissions and removals data for blue carbon ecosystems remains incomplete, and guidelines for monitoring, accounting, etc. are not readily available, blue carbon collaboration can be advanced by using coastal ecosystems protection as climate finance projects in the East Asia blue economy and constructing carbon crediting mechanisms. Regional and global organizations and initiatives, such as PEMSEA, the Blue Carbon Initiative, the Partnership for Blue Carbon and others, can also help to facilitate further cooperation. The blue carbon report published by PEMSEA suggest that PEMSEA countries can take a framework of actions to advance the management of blue carbon ecosystems, climate response planning, blue economy growth and facilitate regional and cross-border blue carbon collaboration, which includes three aspects of awareness building, knowledge exchange and acceleration of practical actions. During the building of awareness, countries can include blue carbon into their policy dialogue, applying the 2013 Intergovernmental Panel on Climate Change (IPCC) wetland supplement in their nation and report trends of coastal ecosystems' status, threats and change through time. By contributing to technical and policy workshops, supporting science programs and technical analysis and developing knowledge products and demonstration activities, PEMSEA countries can facilitate relevant knowledge exchange. As to acceleration of practical action, including blue carbon ecosystems in national economic development plans, correlating health of blue carbon ecosystems with industry inputs and outputs of blue economy and including management of blue carbon ecosystems within coastal management plans can be efficient [12]. Thus, it is realistic to promote blue carbon cooperation along the MSR.

In June 2017, the Chinese government issued the "One Belt and One Road Maritime Cooperation Vision", clearly proposing the idea of "strengthening cooperation on oceans to cope with climate change" and "strengthening international cooperation in blue carbon". Currently, the Chinese government is actively leading the countries along the MSR with the focus on blue carbon cooperation to jointly address climate change and manage the international environment. Based on this, Wang [34] analyzed the significance of the development of blue carbon in Guangdong Province of China to control 
greenhouse gas emissions, protect the marine ecological environment and implement the "Belt and Road" construction, and gave the main paths and measures as solutions for the development of blue carbon in Guangdong Province. Zhang [13] analyzed the national blue carbon cooperation mechanism along the MSR, including three aspects: the driving force mechanism mainly based on the common aspiration of governments to jointly manage the global climate environment; the realization mechanism includes cooperation and protection of marine biodiversity and marine environments, cooperation monitoring of blue carbon ecosystem and cooperative management of marine pollution; guarantee mechanism includes blue carbon cooperation research, high-level ocean dialogue, blue carbon cooperative financing, blue carbon market construction, blue carbon financial support and blue carbon industry support. It can be seen that some scholars have paid attention to the relationship between the MSR and blue carbon, and provide a technical basis and scientific basis for the efficiency improvement of blue carbon cooperation, and offer technical support for the blue carbon cooperation of the MSR. However, as mentioned earlier, the social nature of blue carbon cooperation and the guarantee mechanism for sustainable development are still at an early stage of exploration, and the specific implementation of the blue carbon international cooperation has not been proposed. It is necessary to provide scientific solutions and explore the impact of the influencing factors.

Analogous to the approach of Arctic environmental governance, Fan et al. [35] studied the cooperative behavior of arctic governance among countries in a complex network based on the evolutionary game model, and drew the conclusion that some factors have an impact on the behavior choice of countries, and provided a reference for China's participation in arctic environmental governance and decision-making. By introducing the incentive mechanism of human social organizations, Xie [36] found that the incentive mechanism generally promotes the evolution of cooperative behavior in different network structures. Since that the participants in blue carbon cooperation have behaviors of learning and imitating [37], it is feasible to use a game model. This kind of behavior can be explained by the strategy update and network topology involved in the evolutionary game research. However, the general evolutionary game model is always based on the assumption of rational economic man [38], which is unrealistic. Considering the differences in various aspects of decision-making participants, it is more realistic and convincing to introduce the structural model of decision-making rules into the game model to simulate the strategic choices of various countries in blue carbon cooperation, and provide reference for the blue carbon cooperation and alleviate carbon emissions as possible.

\section{Method and Model Analysis}

\subsection{Research Scope}

In this paper, 30 countries, as shown in Table 2, were selected as the research countries of the blue carbon cooperation along the MSR. All the selected countries are located along the "21st Century Maritime Silk Road". Regional divisions and trade data of these countries can been found in the China Belt and Road Network (https://www.yidaiyilu.gov.cn/).

Table 2. List of countries along the Maritime Silk Road (MSR).

\begin{tabular}{ll}
\hline Region & Countries \\
\hline West Asia and North & Bahrain, Egypt, Iran, Israel, Kuwait, Lebanon, Oman, Qatar, Saudi Arabia, Syria, \\
Africa & Turkey, United Arab Emirates, Yemen \\
\hline South Asia & Bangladesh, India, Maldives, Pakistan, Sri Lanka. \\
\hline \multirow{2}{*}{ East Asia } & Brunei, Cambodia, China, East Timor, Indonesia, Laos, Malaysia, Myanmar, \\
& Philippines, Singapore, Thailand, Vietnam \\
\hline
\end{tabular}




\subsection{Construction of the Blue Carbon Cooperation Network of the MSR}

In 2009, UNESCO, the Intergovernmental Oceanographic Commission, and the World Conservation Union jointly launched the Blue Carbon Initiative, which aims to promote the management of coastal ecosystems, reduce global Carbon emissions, and mitigate the trend of climate global warming through international cooperation. The Initiative has received responses from many countries and has begun to take shape [39]. Since the cooperation between the countries along the MSR is mainly based on economic and trade cooperation - and the production of any kind of product will directly and indirectly produce carbon emissions to a certain extent, the complex network of blue carbon cooperation of the MSR is constructed based on the current economic and trade cooperation between countries. From the United Nations Conference on Trade and Development database (http://unctad.org/en/Pages/statistics.aspx), the bilateral trade data in 2017 of the 30 countries shown in Table 2 were found. We apply the trade volume of US $\$ 50$ million as a threshold, and assume that there is a blue carbon cooperation relationship between the two countries that exceeds the threshold; otherwise, there is no blue carbon cooperation. UCINET software was used to draw the blue carbon cooperation network shown in Figure 1.

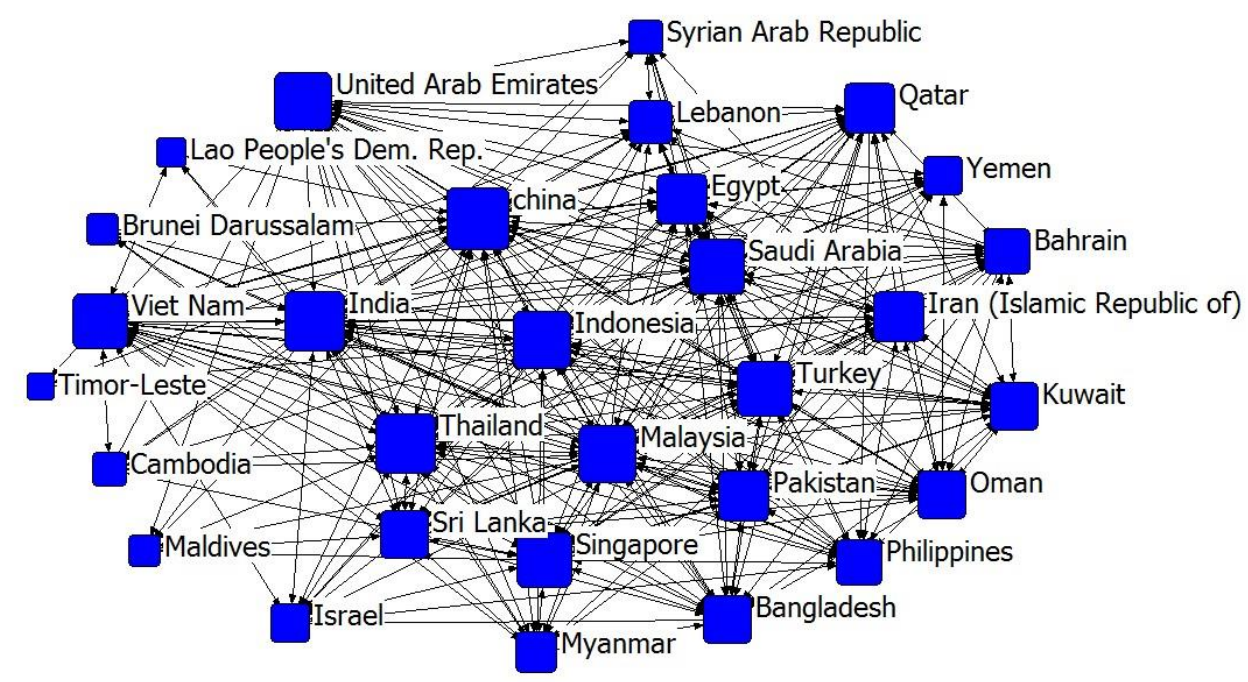

Figure 1. Diagram of the complex network of blue carbon cooperation among countries along the Maritime Silk Road (MSR).

\subsection{The Network Game Model Design of the Blue Carbon Cooperation of the MSR}

In the 1950s, Simon [40] proposed a bounded rational model, arguing that the complete rational decision theory based on the "economic man" hypothesis is just an ideal state, and it is impossible to guide actual decision-making. Due to information barriers, cognitive levels and structural deviations and policy time lags, countries along the MSR in the decision-making process of blue carbon cooperative game cannot completely accord with the rational economic man hypothesis, but will make bounded rational choices. Therefore, introducing the structural model of decision rules into the blue carbon cooperation strategy selection process will provide a more realistic interpretation than the simple complete rational economic man hypothesis game model. Also, differences in the size and strength of countries along the MSR lead to differences in their ability to cooperate on blue carbon. Instead of playing games with all countries in the network, countries often choose to cooperate with countries that have better political, economic and geographical relations with them. In other terms, each country only plays games with neighboring countries that are closely related to it, and thus obtains the maximum game income. In addition, the mutual punishment mechanism between countries is to suppress certain countries' inappropriate economic or political behavior by increasing the tariff rate or adding a new tax. For blue carbon, setting a carbon tax penalty mechanism to reduce the carbon emissions of countries 
with close trade links with them is feasible. It may be an important action to reduce carbon emissions and promote blue carbon production cooperation.

\subsubsection{Basic Decision-Making Rules Structured Model}

Stahl and Wilson [41] proposed a model that differentiates participants by different levels of strategic complexity. They list three levels of reasoning-zero-level reasoners, k-level reasoners, and reasoners of k-1 level. Participants of different types have different strategies in repeated games, and some new rules are introduced into the structured model of decision rules. The formula for this model is as follows:

$$
q_{j}(\mu, \varepsilon)=\frac{\varepsilon \cdot e^{\mu U_{j} P_{0}}}{\sum_{k} e^{\mu U_{k} P_{0}}}+(1-\varepsilon) P_{j}^{\text {nash }}
$$

In the model, $\varepsilon$ represents the proportion of perceived non-nash equilibria, $q_{j}$ represents a belief group, $\mu$ represents noise perceived from other country's choices, $P_{j}^{\text {nash }}$ represents the probability of nash equilibrium choice, $P_{0}$ represents the belief that the initial strategy conforms to uniform distribution, and $U_{j}$ represents the payoff of strategy $j . P_{j}^{\text {nash }}$ is determined by Equation (2), where $\gamma$ denotes the noise in the participant's own choice.

$$
P_{j}(\gamma, \mu, \varepsilon)=e^{\gamma y_{j}(\mu, \varepsilon)} / \sum_{k} e^{\gamma y_{k}(\mu, \varepsilon)}
$$

The value of $y_{j}$ in Equation (2) is determined by Equation (3):

$$
y_{i}(\mu, \varepsilon)=U_{j} q_{j}(\mu, \varepsilon)
$$

Based on this model, Stahl and Wilson [41] set up five types of participant as follows:

(1) level 0 type selects each strategy according to equal probability, where $\gamma$ is 0 ;

(2) level 1 type assumes everyone else is level 0 type, $\mu=0, \varepsilon=1, \gamma>0$;

(3) level 2 type assumes everyone else is level 1 type, $\mu>0, \varepsilon=1, \gamma>0$;

(4) naive nash equilibrium type believes that everyone else will choose nash equilibrium, $\varepsilon=0$, $\gamma>0$;

(5) the smart nash equilibrium type believes that some country will choose the nash equilibrium, but others will calculate the expected payment from the $P_{0}$ belief or the optimal response, $0<\varepsilon<1$, $\gamma>0$.

Subsequently, Costa-Gomes et al. [42] improved the model, divided the decision structure types into naive, optimistic, pessimistic and altruistic types, and identified the rules of the five decision types. The structured model of decision rules shows that different types of decision makers appear with different frequency, the payment and income are different, and the optimal strategy chosen by the decision makers is not the same. At the same time, the model also incorporates the information search observation mode into the game, and gives a better explanation of the results of some endogenous factors and information factors influencing the decision-making.

\subsubsection{Model Assumptions}

In the blue carbon cooperation network diagram of the MSR shown in Figure 1, each node represents a country. We make the following assumptions for the game model of the blue carbon cooperation network:

Hypothesis 1: In the game model of public goods based on the preference mechanism, each node in the network group will imitate the neighbor individual with a higher probability [43]. Therefore, regardless of the impact of the scale of the MSR countries on the blue carbon production, it is assumed that all node countries have 
similar risk preferences. Each node country has two strategic choices-cooperation and non-cooperation, which means whether to participate in the blue carbon initiative or not. $s_{i}=\{0,1\}$ represents the strategy set of node $i$, 1 represents the cooperative strategy, and 0 represents the non-cooperative strategy.

Hypothesis 2: Each country is only affected by the neighborhood countries, and mainly has contact and influence with its neighbors. Defining that node $i$ in the network needs to participate in the $K_{i}+1$ round game in a complete game, where 1 is a round of game with oneself as the center and neighbors as participants; $K_{i}$ is $K_{i}$ round games with neighboring countries as the center and node $i$ and their neighbor as participants, where $K_{i}$ is the degree of node $i$, observe the results.

Hypothesis 3: Use the adjacency matrix A to represent the MSR trade network structure. If there is a relation between node $i$ and node $j, A_{i j}$ is 1 , otherwise 0.

Hypothesis 4: The production of blue carbon is costly. According to the fair mechanism, it is assumed that the initial investment cost of node countries when they choose to cooperate in a round of game is $c, c>0$. By using cost $c$ to plant mangroves, salt marinas, seaweed beds and other coastal vegetation, the blue carbon sink can be increased. The cooperative node then inputs the fixed cost d every year from the second year within the average life span of these coastal plants. The fixed cost d increases the efficiency of blue carbon production, and the output obtained each year also increases on the original basis. Considering the time value of input cost, the total cost in present value of node $i$ in each time of $K_{i}+1$ rounds game is:

$$
C^{t}=\left(K_{i}+1\right) s_{i}^{t} c_{i}^{t}+\sum_{n=2}^{k} \frac{\left(K_{i}+1\right) s_{i}^{t} d}{(1+r)^{n-1}}
$$

when $s_{i}^{t}=1$ :

$$
C^{t}=\left(K_{i}+1\right) c_{i}^{t}+\sum_{n=2}^{k} \frac{\left(K_{i}+1\right) d}{(1+r)^{n-1}},
$$

when $s_{i}^{t}=0$, the total cost of $C^{t}$ is 0 . Among them, the average life span of coastal vegetation is $k$ years, which is the number of years the return can be generated when the node is chosen to cooperate in this game; and $r$ is the discount rate of future income, assuming it is a fixed value, based on the current economic inflation trend, $r>0$.

Hypothesis 5: The annual output of coastal plants planted in the survival years is uniform, and the investment return of blue carbon production obtained by node $i$ is a linear function of cost, and is expressed as the average return. The investment cost of all neighbor nodes and central nodes is multiplied by a return factor $\lambda, \lambda>0$, and then the returns are equally divided among all game participants.

As the central node, the present value of the game income obtained during a round of game by $i$ is:

$$
f^{t}=\sum_{n=1}^{k} \frac{\lambda\left[\left(\sum_{j=1}^{N} A_{i j} s_{j}^{t} c_{j}+s_{i}^{t} c_{i}\right)+\left(\sum_{j=1}^{N} A_{i j} s_{j}^{t}+s_{i}^{t}\right)(n-1) d\right] /\left(K_{i}+1\right)}{(1+r)^{n}}
$$

So is its neighbor $j$.

When $s_{i}^{t}=1$ :

$$
f_{i=1}^{t}=\sum_{n=1}^{k} \frac{\lambda\left[\left(\sum_{j=1}^{N} A_{i j} s_{j}^{t} c_{j}+c_{i}\right)+\left(\sum_{j=1}^{N} A_{i j} s_{j}^{t}+1\right)(n-1) d\right] /\left(K_{i}+1\right)}{(1+r)^{n}},
$$

when $s_{i}^{t}=0$ :

$$
f_{i=0}^{t}=\sum_{n=1}^{k} \frac{\lambda\left[\sum_{j=1}^{N} A_{i j} s_{j}^{t} c_{j}+\sum_{j=1}^{N} A_{i j} s_{j}^{t}(n-1) d\right] /\left(K_{i}+1\right)}{(1+r)^{n}} .
$$


The neighboring node $j$ of node $i$ is the central node, the neighbor of node $j$ is the node $i$, and the present value of the income obtained by $K_{i}$ rounds game when $i$ as the participating country is:

$$
f^{\prime t}=\sum_{n=1}^{k} \frac{\sum_{j=1}^{N} A_{i j} \frac{\lambda\left[\left(\sum_{l \in n, l \neq c} A_{j l} s_{l}^{t} c_{l}+s_{j}^{t} c_{j}+s_{i}^{t} c_{i}\right)+\left(\sum_{l \in n, l \neq c} A_{j l} s_{l}^{t}+s_{j}^{t}+s_{i}^{t}\right)(n-1) d\right]}{\left(K_{j}+1\right)}}{(1+r)^{n}},
$$

when $s_{i}^{t}=1$ :

$$
f_{i=1}^{\prime t}=\sum_{n=1}^{k} \frac{\sum_{j=1}^{N} A_{i j} \frac{\lambda\left[\left(\sum_{l \in n, l \neq c} A_{j l} s_{l}^{t} c_{l}+s_{j}^{t} c_{j}+c_{i}\right)+\left(\sum_{l \in n, l \neq c} A_{j l} s_{l}^{t}+s_{j}^{t}+1\right)(n-1) d\right]}{\left(K_{j}+1\right)}}{(1+r)^{n}},
$$

when $s_{i}^{t}=0$ :

$$
f_{i=0}^{\prime t}=\sum_{n=1}^{k} \frac{\sum_{j=1}^{N} A_{i j} \frac{\lambda\left[\left(\sum_{l \in n, l \neq c} A_{j l} s_{l}^{t} c_{l}+s_{j}^{t} c_{j}\right)+\left(\sum_{l \in n, l \neq c} A_{j l} s_{l}^{t}+s_{j}^{t}\right)(n-1) d\right]}{\left(K_{j}+1\right)}}{(1+r)^{n}} .
$$

Hypothesis 6: In the complex network, regardless of the network structure, the incentive mechanism generally shows the promotion of cooperative behavior [36]. Therefore, in the blue carbon cooperation network of the MSR, in order to eliminate the "free rider" problem of the neighboring countries in the blue carbon cooperation project, the node countries that choose the cooperation strategy will provide economic incentives to neighboring nodes which are engaged in blue carbon investment. When node i chooses the cooperation strategy, it can obtain certain rewards and subsidies from the neighbor nodes in the network. Assuming that the subsidy rate provided by each cooperative neighboring country is $v, v>0$, then the total reward amount obtained by the node $i$ is $s_{i}^{t} v \sum_{j=1}^{N} s_{j}^{t} A_{i j} Q_{i}$, where $Q_{i}$ is the area of the coastal plant newly planted by the node $i$ in the game.

Hypothesis 7: The carbon emission of exporting countries increases continuously with the expansion of export scale [44], and there is an increasingly urgent need to reduce carbon emissions. According to the research, under effective carbon tax policies, enterprises would gradually transform to a low energy consumption strategy [45]. In order to promote blue carbon environmental governance and reduce carbon pollution, countries in the blue carbon cooperation network of the MSR will reach some consensus to impose economic penalties on the corresponding trade behaviors by means of carbon tax. The carbon tax rate formed from this is assumed to be $u_{i}$, $0<u_{i}<1$. The final tax is related to the trade volume $X_{C_{i}}-M_{C_{i}}$ of the country's net export to the carbon-related commodities of the neighboring countries in the economic cooperation relationship of the MSR. Then the total tax that the node $i$ needs to pay is $u_{i} \times \sum_{j=1}^{N} A_{i j}\left(1-s_{i}^{t} \beta\right)\left(X_{C_{i}}-M_{C_{i}}\right)$, where $X_{C_{i}}$ is carbon commodity export quantity, $M_{C_{i}}$ is the carbon import commodity quantity, and when $X_{C_{i}}-M_{C_{i}}<0$, node $i$ can obtain carbon tax revenue. It should be noted that when $s_{i}^{t}=1$, which means node $i$ chooses the cooperation strategy, the country considering the environmental protection will reduce the import and export of carbon products. The carbon-containing commodity amount at this time is $(1-\beta)$ times the amount of carbon-containing commodities in the case of non-cooperation, and $\beta$ is a reduction ratio of the carbon-containing commodity amount at the time of cooperation, and $0<\beta<1$. 
According to the hypotheses above, the total benefits of nodal country $i$ in game $t$ are composed of three parts: the proceeds from the planting of the coastal plants, cooperative subsidies given by neighbors, and carbon tax:

$$
f_{i t}=f^{t}+f^{\prime t}-C^{t}+s_{i}^{t} v \sum_{j=1}^{N} s_{j}^{t} A_{i j} Q_{i}-u_{i} \sum_{j=1}^{N} A_{i j}\left(1-s_{i}^{t} \beta\right)\left(X_{C_{i}}-M_{C_{i}}\right) .
$$

Thus in the $t$-th time game, the benefits obtained by choosing two different strategies for node $i$ are as follows:

$$
f_{i t}= \begin{cases}f_{i=1}^{t}+f_{i=1}^{\prime t}-C^{t}+v \sum_{j=1}^{N} s_{j}^{t} A_{i j} Q_{i}-u_{i} \sum_{j=1}^{N}(1-\beta) A_{i j}\left(X_{C_{i}}-M_{C_{i}}\right) & s_{i}^{t}=1 \\ f_{i=0}^{t}+f_{i=0}^{\prime t}-u_{i} \sum_{j=1}^{N} A_{i j}\left(X_{C_{i j}}-M_{C_{i j}}\right) & s_{i}^{t}=0\end{cases}
$$

Table 3 provides the symbolic meanings of Equations (4) to (7).

Table 3. Symbolic meanings of Equations (4) to (7).

\begin{tabular}{ll}
\hline Symbols & Implications \\
\hline$A_{i j}$ & The network connection relation of nodes $i$ and $j$, take value 1 or 0 \\
$s_{i}^{t}, s_{j^{t}}, s_{l}^{t}$ & The strategy adopted by nodes $i, j, l$ \\
$C^{t}$ & The total cost present value of node $i$. for $t$ games, including the initial input cost $c$ and the \\
$r$ & annual cost of input $d$ \\
$\lambda$ & Discount rate of future earnings \\
$v$ & Return coefficient of cost \\
$Q_{i}$ & Cooperative subsidy rate from neighbors \\
$u_{i}$ & Newly planted coastal plants of node $i$ \\
$X_{C_{i}}-M_{C_{i}}$ & The carbon tax rate of node $i$ net export to neighboring countries \\
$\beta$ & Net exports of carbon-containing commodities to neighboring countries of node $i$ \\
\hline & The proportion of the reduction of carbon commodity quantity when choosing cooperation \\
\hline
\end{tabular}

\subsubsection{Model Analysis}

By analyzing the total return formula, the carbon sink payment income, which is $f^{t}+f^{t}-C^{t}$, generated by planting coastal plants in the blue carbon cooperative game under different conditions, can be obtained as follows:

When the central node $i$ chooses cooperation, and the neighboring node $j$ also chooses cooperation, the carbon sink payment benefit is:

$$
\begin{aligned}
& U_{i 11}^{t}=f_{i 11}^{t}+f_{i 11}^{\prime t}-C^{t} \\
& =\sum_{n=1}^{k} \frac{\lambda\left[\sum_{j=1}^{N} A_{i j} c+c+\left(\sum_{j=1}^{N} A_{i j}+1\right)(n-1) d\right] / K_{i}+1}{(1+r)^{n}}
\end{aligned}
$$

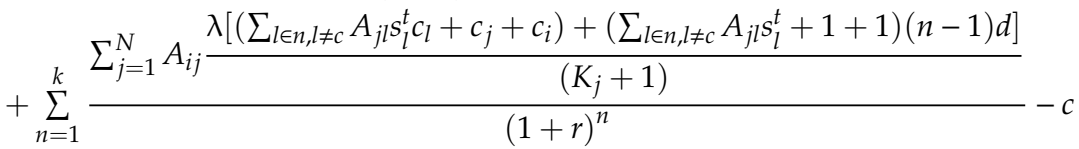

$$
\begin{aligned}
& -\sum_{n=2}^{k} \frac{d}{(1+r)^{n-1}} \\
& U_{j 11}^{t}=U_{i 11}^{t}
\end{aligned}
$$


when center node $i$ chooses cooperation while neighbor node $j$ chooses not to cooperate, the payment income is:

$$
\begin{aligned}
& U_{i 10}^{t}=f_{i 10}^{t}+f_{i 10}^{\prime t}-C^{t} \\
& =\sum_{n=1}^{k} \frac{\lambda[c+(n-1) d] / K_{i}+1}{(1+r)^{n}} \\
& +\sum_{n=1}^{k} \frac{\sum_{j=1}^{N} A_{i j} \frac{\lambda\left[\left(\sum_{l \in n, l \neq c} A_{j l} l_{l}^{t} c_{l}+c_{i}\right)+\left(\sum_{l \in n, l \neq c} A_{j l} l_{l}^{t}+1\right)(n-1) d\right]}{\left(K_{j}+1\right)}}{(1+r)^{n}}-c \\
& -\sum_{n=2}^{k} \frac{d}{(1+r)^{n-1}} \\
& U_{j 10}^{t}=f_{j 10}^{t}+f_{j 10}^{\prime t} \\
& =\sum_{n=1}^{k} \frac{\lambda[c+(n-1) d] / K_{i}+1}{(1+r)^{n}} \\
& +\sum_{n=1}^{k} \frac{\sum_{j=1}^{N} A_{i j} \frac{\lambda\left[\left(\sum_{l \in n, l \neq c} A_{j l} l_{l}^{t} c_{l}+c_{i}\right)+\left(\sum_{l \in n, l \neq c} A_{j l} l_{l}^{t}+1\right)(n-1) d\right]}{\left(K_{j}+1\right)}}{(1+r)^{n}}
\end{aligned}
$$

when center node $i$ chooses non-cooperation while neighbor node $j$ chooses to cooperate, the payment income is:

$$
\begin{aligned}
& U_{i 01}^{t}=f_{i 01}^{t}+f_{i 01}^{t} \\
& =\sum_{n=1}^{k} \frac{\lambda\left[\left(\sum_{j=1}^{N} A_{i j} c_{j}+\sum_{j=1}^{N} A_{i j}(n-1) d\right] /\left(K_{i}+1\right)\right.}{(1+r)^{n}} \\
& +\sum_{n=1}^{k} \frac{\sum_{j=1}^{N} A_{i j} \frac{\lambda\left[\left(\sum_{l \in n, l \neq c} A_{j l} l_{l}^{t} c_{l}+c_{j}\right)+\left(\sum_{l \in n, l \neq c} A_{j l} l_{l}^{t}+1\right)(n-1) d\right]}{\left(K_{j}+1\right)}}{(1+r)^{n}} \\
& U_{j 10}^{t}=f_{j 10}^{t}+f_{j 10}^{\prime t}-C^{t} \\
& =\sum_{n=1}^{k} \frac{\lambda\left[\left(\sum_{j=1}^{N} A_{i j} c_{j}+\sum_{j=1}^{N} A_{i j}(n-1) d\right] /\left(K_{i}+1\right)\right.}{(1+r)^{n}} \\
& +\sum_{n=1}^{k} \frac{\sum_{j=1}^{N} A_{i j} \frac{\lambda\left[\left(\sum_{l \in n, l \neq c} A_{j l} l_{l}^{c_{l}} c_{l}+c_{j}\right)+\left(\sum_{l \in n, l \neq c} A_{j l} s_{l}^{t}+1\right)(n-1) d\right]}{\left(K_{j}+1\right)}}{(1+r)^{n}}-c \\
& -\sum_{n=2}^{k} \frac{d}{(1+r)^{n-1}},
\end{aligned}
$$

when center node $i$ chooses non-cooperation, adjacent node $j$ chooses non-cooperation, the payment from the planning of coastal plant is 0 :

$$
U_{i 00}^{t}=0 ; U_{j 00}^{t}=0 .
$$

By substituting the above profit value into Equation (1), the belief group $q_{j D}$ of countries with $j$ node adopting betrayal strategy can be obtained:

$$
q_{j D}=\varepsilon \frac{\exp \left[\mu\left(P_{0} U_{j 10}+P_{0} U_{j 00}\right)\right]}{\exp \left[\mu\left(P_{0} U_{j 11}+P_{0} U_{j 01}\right)\right]+\exp \left[\mu\left(P_{0} U_{j 10}+P_{0} U_{j 00}\right)\right]}+(1-\varepsilon) P_{j}^{n a s h} .
$$

According to Equation (15), it can be concluded that the belief group of node $j$ countries to adopting cooperation strategy is:

$$
q_{j C}=1-q_{j D}
$$


Then the expected payment $y_{j c}$ when the $j$ node adopts the cooperation strategy is:

$$
y_{j C}=q_{j C} U_{j 11}+q_{j D} U_{j 01} .
$$

When $j$ adopts the non-cooperation strategy, the expected payment $y_{j D}$ is:

$$
y_{j D}=q_{j c} U_{j 10}+q_{j D} U_{j 00} .
$$

Equations (17) and (18) are substituted into Equation (2) to obtain the probability that game party node $j$ adopts a non-cooperative strategy:

$$
P_{j D}=\frac{\exp \left(\gamma y_{j D}\right)}{\exp \left(\gamma y_{j C}\right)+\exp \left(\gamma y_{j D}\right)} .
$$

Equation (19) represents the probability that game party node $j$ adopts an uncooperative strategy; the probability that it adopts the nash equilibrium strategy is:

$$
P_{j D}=P_{j}^{\text {nash }} .
$$

The node countries are rational decision makers. Under the initial conditions, they will choose the nash equilibrium strategy, so $P_{j}^{\text {Nash }}=1$. Participants will continuously adjust their strategic behaviors according to the income situation in the network. When the cooperation income is greater than the non-cooperative income, the node countries will adopt the cooperation strategy; otherwise, they will adjust to the non-cooperative strategy.

Substitute Equations (15)-(17) into Equation (7), and the equilibrium condition of nodal country $i$ in $t$-th game is obtained as Equation (21):

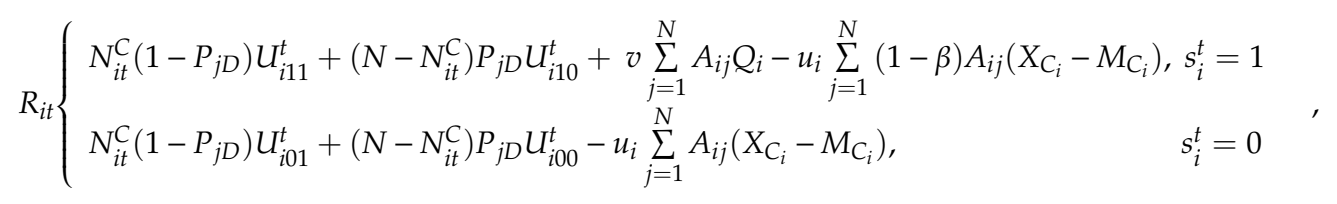

where $N$ represents the total number of nodes, $N^{C}$ represents the number of partners, and $P_{j D}$ represents the belief that node $i$ takes a betrayal strategy against node $j$. The equilibrium condition for node $i$ to select cooperation strategy is that the benefits of cooperation are greater than or equal to the benefits of betrayal, as shown in Equation (22):

$$
\begin{aligned}
& N_{i t}^{C}\left(1-P_{j D}\right) U_{i 11}+\left(N-N_{i t}^{C}\right) P_{j D} U_{i 10}+v \sum_{j=1}^{N} A_{i j} Q_{i}-u_{i} \sum_{j=1}^{N}(1-\beta) A_{i j} \\
& \left(X_{C_{i}}-M_{C_{i}}\right) \geq N_{i t}^{C}\left(1-P_{j D}\right) U_{i 01}+\left(N-N_{i t}^{C}\right) P_{j D} U_{i 00}-u_{i} \sum_{j=1}^{N} A_{i j}\left(X_{C_{i}}-M_{C_{i}}\right) .
\end{aligned}
$$

By expanding Equation (22), the conditions for country $i$ to choose cooperation strategy can be obtained, as shown in Equation (23):

$$
\begin{aligned}
N_{i t}^{C}\left(1-P_{j D}\right) & {\left[\sum_{n=1}^{k} \frac{\lambda\left[\sum_{j=1}^{N} A_{i j} c+c+\left(\sum_{j=1}^{N} A_{i j}+1\right)(n-1) d\right] / K_{i}+1}{(1+r)^{n}}-c-\sum_{n=2}^{k} \frac{d}{(1+r)^{n-1}}\right] } \\
& +\left(N-N_{i t}^{C}\right) P_{j D}\left[\sum_{n=1}^{k} \frac{\lambda[c+(n-1) d] / K_{i}+1}{(1+r)^{n}}-c-\sum_{n=2}^{k} \frac{d}{(1+r)^{n-1}}\right] \\
& +v \sum_{j=1}^{N} A_{i j} Q_{i}-u_{i} \sum_{j=1}^{N}(1-\beta) A_{i j}\left(X_{C_{i}}-M_{C_{i}}\right) \\
& -N_{i t}^{C}\left(1-P_{j D}\right) \sum_{n=1}^{k} \frac{\lambda\left[\sum_{j=1}^{N} A_{i j} c+\sum_{j=1}^{N} A_{i j}(n-1) d\right] / K_{i}+1}{(1+r)^{n}} \\
& +u_{i} \sum_{j=1}^{N} A_{i j}\left(X_{C_{i}}-M_{C_{i}}\right) \geq 0 .
\end{aligned}
$$


It can be shown from Equation (23) that the choice of a certain round of game strategy in each node country of the MSR blue carbon cooperation network is directly related with the cost of cooperation input $c$, the cost-return coefficient $\lambda$, the discount rate of income $r$, reward rate provided by neighbor nodes for cooperation $\mathrm{v}$, the size of the gain from the node selection betrayal strategy, and the blue carbon tax rate when not cooperating. The higher the rate of return is, the more likely Equation (23) is to be established, and the more likely node countries are to choose cooperative strategies. The greater the cooperative rewards given by neighboring countries, the greater the possibility that node countries choose cooperative strategies. Also, it seems that the higher the carbon tax rate charged by the network for non-cooperative member states, the higher the cost of non-cooperation, and the easier the establishment of Equation (23); thus, cooperation will become the rational choice of the node countries. At the same time, the probability that node $j$ chooses nash equilibrium strategy also has a significant impact on the choice of cooperative strategy.

\section{Network Game Simulation of Blue Carbon Cooperation along the MSR}

\subsection{Simulation Process}

The complex network of blue carbon cooperation is quantified as a 01-relation matrix, where the value of the corresponding position in the matrix table with connection relation between countries is expressed as 1, otherwise it is 0 . The matrix figure is shown in Figure 2:

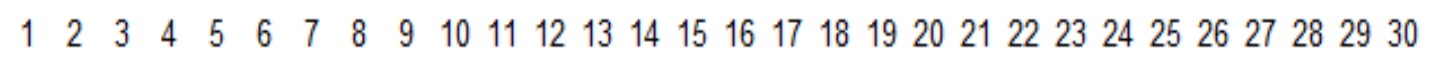

\begin{tabular}{|c|c|c|c|c|c|c|c|c|c|c|c|c|c|c|c|c|c|c|c|c|c|c|c|c|c|c|c|c|c|c|}
\hline 1 & 0 & 1 & 0 & 0 & 1 & 1 & 1 & 1 & 0 & 0 & 1 & 0 & 1 & 1 & [ी & 0 & 1 & 1 & 1 & 1 & 1 & 1 & 0 & 0 & 1 & 0 & 1 & 1 & 0 & \\
\hline 2 & 0 & 0 & 0 & 0 & 1 & 0 & 1 & & & & & & & & & & & & & & & 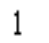 & & & 0 & & & & & \\
\hline 3 & 0 & 0 & U & 0 & 1 & 0 & 1 & 0 & 0 & 0 & 0 & & & 1 & & & & & & & & 1 & & & 1 & & & & & \\
\hline 4 & 0 & 0 & 0 & 0 & 1 & 0 & 0 & 0 & 0 & 0 & 0 & 0 & 0 & 1 & 0 & 0 & 0 & 0 & 0 & 0 & 0 & 1 & 0 & 0 & 1 & & 0 & 1 & 1 & \\
\hline 5 & 1 & 1 & 1 & 1 & 0 & 1 & 1 & 1 & 1 & 1 & 1 & 1 & 1 & 1 & 1 & 1 & 1 & 1 & 1 & 1 & 2 & 1 & 1 & $x^{2}$ & 1 & 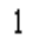 & 1 & 1 & 1 & \\
\hline 6 & 1 & 1 & 0 & 0 & 1 & 0 & 1 & 1 & 0 & 1 & 1 & 0 & 1 & 1 & 0 & 0 & 1 & 1 & 0 & 1 & 1 & 1 & 0 & 1 & 1 & 0 & 1 & 1 & 0 & \\
\hline 7 & 1 & 1 & 0 & 1 & 1 & 1 & 0 & 1 & 1 & 1 & 1 & & 1 & 1 & & 1 & 1 & 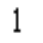 & 1 & 1 & 1 & 1 & 1 & 1 & 1 & 0 & 1 & 1 & 1 & \\
\hline 8 & 0 & 1 & 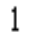 & 1 & 1 & 1 & 1 & 0 & 1 & 1 & 1 & & 1 & 1 & U & 1 & 1 & 1 & 1 & 1 & 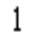 & 1 & 1 & 0 & 1 & 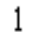 & 1 & 1 & 1 & \\
\hline 9 & 0 & 0 & 0 & 0 & 1 & 1 & 1 & 1 & 0 & 0 & 1 & 0 & 1 & 1 & 0 & 1 & 1 & 1 & 1 & 1 & 1 & 1 & 1 & 1 & 1 & 0 & 1 & 1 & 1 & U \\
\hline 10 & 0 & 0 & 0 & 0 & 1 & 1 & 1 & 1 & 0 & 0 & 0 & 0 & 0 & 0 & 0 & 0 & 0 & 0 & 1 & 0 & 0 & 1 & 0 & 0 & 1 & 0 & 1 & 0 & 1 & U \\
\hline 11 & 1 & 1 & 0 & 0 & 1 & 1 & 1 & 1 & 1 & 0 & 0 & 0 & 1 & 1 & 0 & 0 & 1 & 1 & 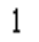 & 1 & 1 & 1 & 0 & 0 & 1 & 0 & 1 & 1 & 1 & \\
\hline 12 & 0 & 0 & 0 & 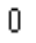 & 1 & 0 & 1 & 0 & 0 & 0 & 0 & 0 & 0 & 0 & & I & 0 & (] & U & U & 0 & 0 & 0 & 0 & 1 & 0 & 0 & 0 & 1 & \\
\hline 13 & 0 & 0 & 0 & 0 & 1 & 1 & 0 & 0 & 0 & 0 & 1 & & 0 & 0 & U & U & 0 & U & U & 1 & 1 & 0 & U & 1 & 0 & & 1 & 1 & & \\
\hline 14 & 1 & 1 & 1 & 1 & 1 & 1 & 1 & 1 & 1 & 0 & 1 & 0 & 1 & 0 & 1 & 1 & 1 & 1 & 1 & 1 & 1 & 1 & 1 & 0 & 1 & 0 & 1 & 1 & 1 & 1 \\
\hline 15 & 0 & 0 & 0 & 0 & 0 & 0 & 0 & 0 & 0 & 0 & 0 & 0 & 0 & 0 & 0 & 0 & 0 & 0 & 0 & 0 & 0 & 0 & 1 & 0 & 1 & 0 & 0 & 0 & 0 & 0 \\
\hline 16 & 0 & 1 & 0 & 0 & 1 & 0 & 1 & 1 & 0 & 0 & 0 & 0 & 0 & 1 & 0 & 0 & 0 & 1 & 0 & 0 & 0 & 1 & 1 & 0 & 1 & 0 & 0 & 1 & 1 & 0 \\
\hline 17 & 1 & 1 & 0 & 0 & 1 & 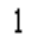 & 1 & 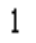 & 1 & 0 & 1 & & 0 & 1 & & 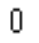 & 0 & 1 & ] & 1 & 1 & 1 & 1 & 0 & 1 & 0 & 1 & 1 & 1 & \\
\hline 18 & 0 & 1 & 0 & 0 & 1 & 1 & 1 & 1 & 0 & 0 & 1 & 0 & 0 & 1 & 0 & 0 & 1 & 0 & 1 & 1 & 1 & 1 & 1 & 0 & 1 & 0 & 1 & 1 & 1 & 1 \\
\hline 19 & 0 & 0 & 0 & 0 & 1 & 0 & 1 & 1 & 1 & 1 & 0 & 0 & 0 & 1 & 0 & 0 & 0 & 1 & 0 & 0 & 1 & 1 & 0 & 0 & 1 & 0 & 1 & 1 & 1 & 0 \\
\hline 20 & 1 & 1 & 0 & 0 & 1 & 1 & 1 & 1 & 0 & 0 & 1 & 0 & 0 & 1 & 0 & 0 & 1 & 1 & 1 & 0 & 1 & 1 & 1 & 0 & 1 & 0 & 1 & 1 & 1 & 0 \\
\hline 2 & 1 & 1 & 0 & 0 & 1 & 1 & 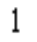 & 1 & 1 & 0 & 1 & 0 & 1 & 1 & 0 & 1 & 1 & 1 & 1 & 1 & 0 & 1 & 1 & 1 & 1 & & 1 & 1 & 1 & . \\
\hline 22 & 1 & 1 & 1 & 1 & 1 & , & 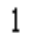 & 1 & 1 & 1 & 1 & 0 & 0 & 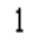 & 1 & 1 & 1 & 1 & 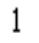 & 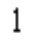 & 1 & 0 & 1 & 0 & 1 & 0 & 1 & 1 & 1 & 0 \\
\hline 23 & 0 & 1 & 0 & 1 & 1 & 0 & 1 & 0 & 1 & 1 & 0 & 0 & 0 & 1 & 1 & 0 & 0 & 1 & 0 & 0 & 1 & 1 & 0 & 0 & 1 & 0 & 1 & 1 & 1 & 0 \\
\hline 24 & 0 & 0 & 0 & 0 & 0 & 0 & O & 0 & 0 & 0 & 0 & 0 & 1 & 0 & 0 & 0 & 0 & 0 & 0 & 0 & 1 & 0 & 0 & 0 & 0 & 0 & 1 & 0 & 0 & 0 \\
\hline 25 & 1 & 1 & 1 & 1 & 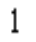 & 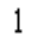 & 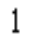 & 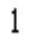 & 1 & 1 & 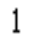 & & 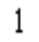 & & 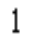 & - & 1 & 1 & 1 & 1 & 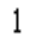 & 1 & 1 & 0 & 0 & 0 & 1 & 1 & 1 & 0 \\
\hline 26 & 0 & 0 & 0 & 0 & 0 & 0 & 0 & 0 & 0 & 0 & 0 & 0 & 0 & 0 & 0 & 0 & 0 & 0 & 0 & 0 & 0 & 0 & 0 & 0 & 0 & 0 & 0 & 0 & 0 & 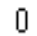 \\
\hline 27 & 1 & 1 & 0 & 0 & 1 & 1 & 1 & 1 & 1 & 1 & 1 & 0 & 1 & 1 & 0 & 0 & 1 & 1 & 1 & 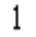 & 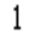 & 1 & 1 & 1 & 1 & 0 & 0 & 1 & 1 & 1 \\
\hline 28 & 1 & 1 & 0 & 0 & - & 1 & 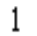 & 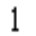 & 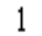 & 0 & . & 0 & - & - & 1 & 1 & - & 1 & 1 & 1 & 1 & 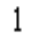 & 1 & 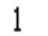 & 1 & 0 & & 0 & 1 & 1 \\
\hline 29 & 0 & 1 & 0 & t & 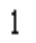 & 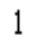 & 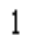 & 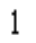 & 0 & 1 & 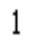 & 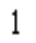 & 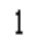 & 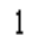 & o & . & o & 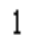 & . & o & 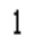 & 1 & 1 & 0 & 1 & 1 & 1 & 1 & 0 & 0 \\
\hline 30 & 0 & 0 & 0 & 0 & 1 & 0 & 0 & 0 & 0 & 0 & 0 & 0 & 0 & & & & & 0 & & & 1 & 0 & 0 & 0 & 1 & U & 0 & 1 & 0 & 0 \\
\hline
\end{tabular}

Ki 1218572661823201311183142271016201616222316825322232110

Figure 2. Network nodes relationship matrix. 
Numbers 1-30 in the matrix represent the selected countries of the Blue Carbon Cooperation Network of the MSR; these are Bahrain, Bangladesh, Brunei, Cambodia, China, Egypt, India, Indonesia, Iran, Israel, Kuwait, Laos, Lebanon, Malaysia, Maldives, Myanmar, Oman, Pakistan, the Philippines, Qatar, Saudi Arabia, Singapore, Sri Lanka, Syria, Thailand, East Timor, Turkey, United Arab Emirates,

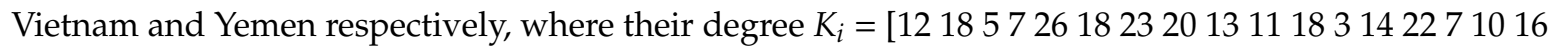
$201616222316825322232110]$.

The model was simulated by MATLAB software. The simulation flow chart is provided in Figure 3:

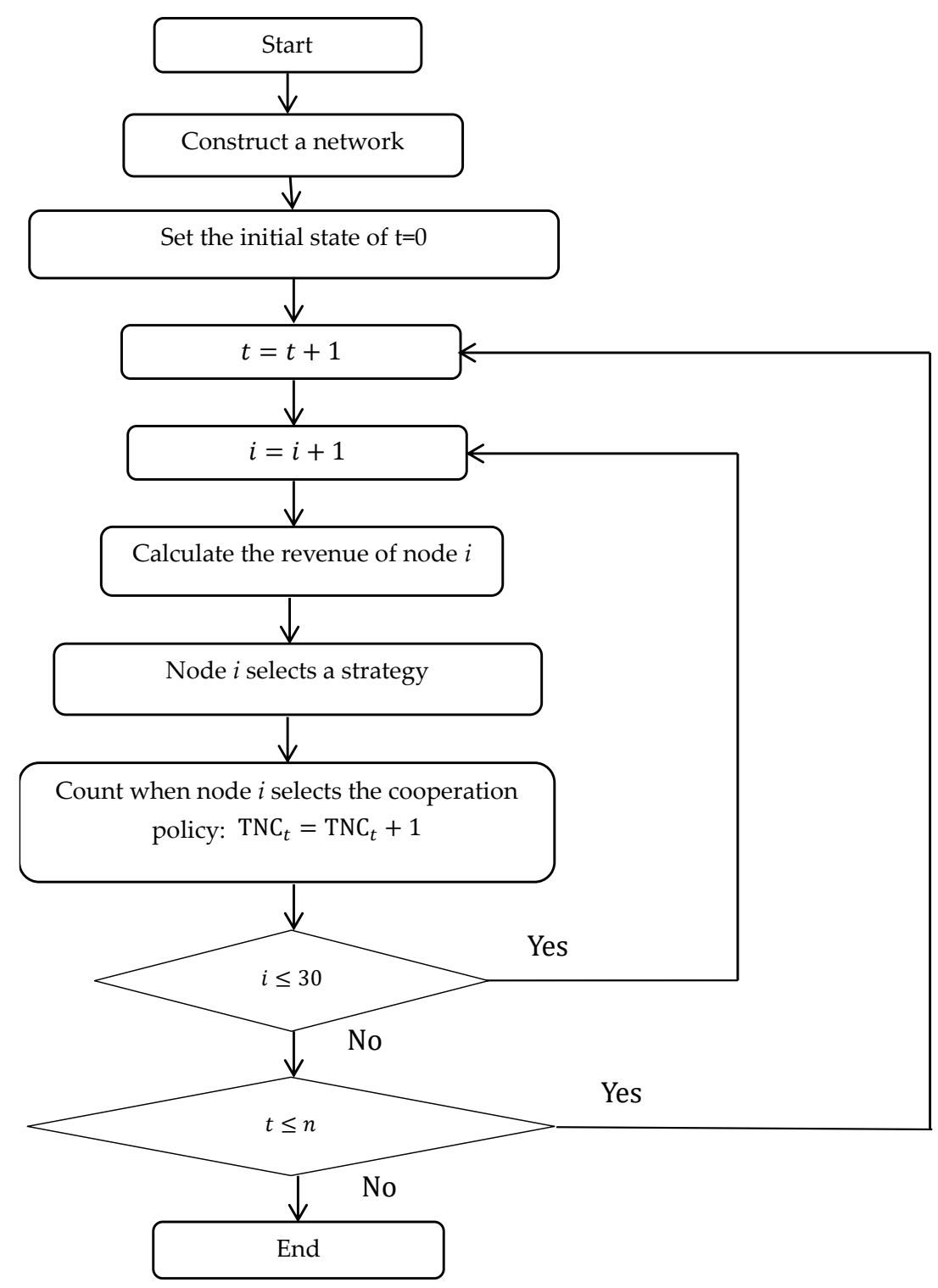

Figure 3. Model simulation flow chart.

\subsection{Simulation Results}

\subsubsection{The Impact of Different Types of Decision Maker on Blue Carbon Cooperation along the MSR}

Assume that the initial input cost of the blue carbon cooperation game on the MSR was 10, the annual fixed input cost was 0.5 , the annual return was is 0.12 , which is includes an interest rate that can be obtained by investing funds in an investment without any risk and considers the inflation rate. The cost-return coefficient was 5 , the average survival period of coastal plants planted per game was 10 years (that is, the income period available for each game is 10 ), the cost subsidy rate given by the 
neighbors is 0.06 , and the carbon tax rate for carbon-containing goods between the countries connected by the MSR was 0.2 . When the cooperation strategy was chosen, the carbon content reduction rate of the commodity was 0.1 . The probability of selection for the two strategies obeys a uniformly distributed belief $P_{0}=0.5$; this means that the initial number of collaborators was 15 . Assume that the values of $\mu$, $\varepsilon, \gamma$ are as follows: 0-level type: $\mu=0.2, \varepsilon=0.05, \gamma=0$; 1-level type: $\mu=0, \varepsilon=1, \gamma=0.2$; 2-level type: $\mu=0.2, \varepsilon=1, \gamma=0.3$; naive nash type: $\mu=0.2, \varepsilon=0, \gamma=0.2$; and smart nash type: $\mu=0.4, \varepsilon=0.2$, $\gamma=0.3$. (The values of these parameters are the values that can achieve the clearest results after many experiments. They can be changed, but the resulting trend is consistent.) The simulation results are shown in Figure 4:

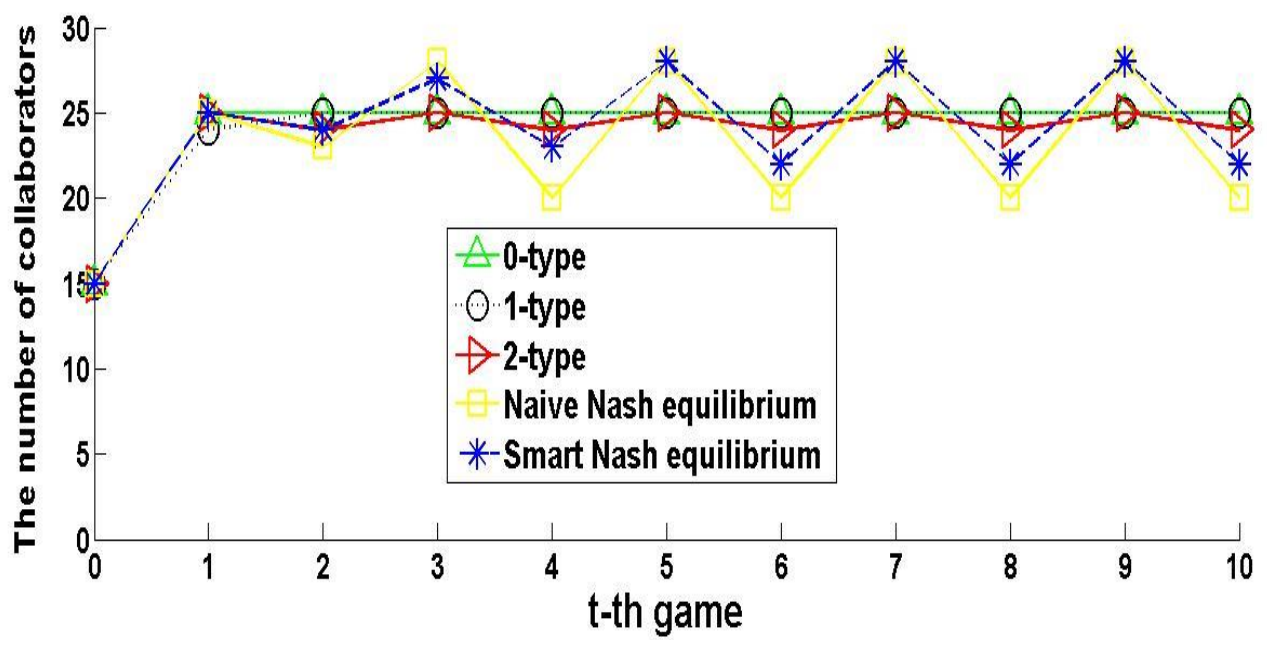

Figure 4. Influence of different types of decision maker on the number of collaborators in the blue carbon cooperative network game of the MSR.

In Figure 4, the type of decision maker has a certain impact on the network game of blue carbon cooperation along the MSR. When all the countries in the network are level-0 decision-makers, from the first game, 25 countries in the network chose cooperative strategies. When all decision makers were of level-1 type, the equilibrium of the network game stabilized from the second game. When all of them were level-2 decision makers, the number of cooperative strategies selected by countries in the network varies between 24 and 25. When all the decision makers were naive nash equilibrium types, the number of partners in the network fluctuated sharply between 20 and 28 . When all the countries were decision makers of smart nash equilibrium type, the number of partners fluctuated up and down from the second game, and the fluctuation range was smaller than that of naive nash equilibrium types. Finally, the number of partners fluctuated periodically between 22 and 28 , when the average number of partners was 25 .

From the above analysis, it can be inferred that the decision-making types of node country influence the strategic choices of countries along the MSR, and thus affect the equilibrium state of network games. The simpler the decision-making structure of a country, the more obvious the tendency to choose cooperative strategies is. The more sophisticated decision makers are, the more difficult it is to reach a consistent solution in network cooperation; at the same time, naive nash equilibrium decision makers will bring more fluctuations in the number of network game partners. In the process of practical cooperation, the countries in the blue carbon cooperation network along the MSR are multidimensional decision-making styles. Countries may have a certain percentage of the smart nash type and have a certain percentage of the structure of national level 0 reasoning; and there could be a percentage of other types of decision maker. With different scale and different types of decision maker in the network game, their cooperation will be at a level 0 structure of reasoning and an astute nash type of intermediate results. 
4.2.2. The Impact of the Initial Input Cost of the Game on the Blue Carbon Cooperation along the MSR

Assume a discount rate of 0.12 for annual returns, a fixed input cost of 0.5 for each year after choosing cooperation, the cost of return coefficient was 3 for each game, a revenue period of 10 for each game, and a cost subsidy rate of 0.06 for neighbors. The carbon tax rate for carbon-containing commodities between the countries linked to the Silk Road trade was 0.2 , and the carbon reduction rate of commodities when the cooperative strategy was 0.1 . The noise perceived by the participants from other country's choices was $\mu=0.1$, and the noise from the participants' own choice was $\gamma=0.2$. The perceived ratio of non-nash equalizers $\varepsilon$ equals to 0.1 . The probability of selection for the two strategies obeys the uniform distribution $P_{0}=0.5$. The game income matrix of the blue carbon environmental protection cooperation node $i, j$ of the MSR is affected by the initial planting cost of $\mathrm{c}$ each game. When c was taken as 0, 2, 6, 15, 20, the simulation results are shown in Figure 5:

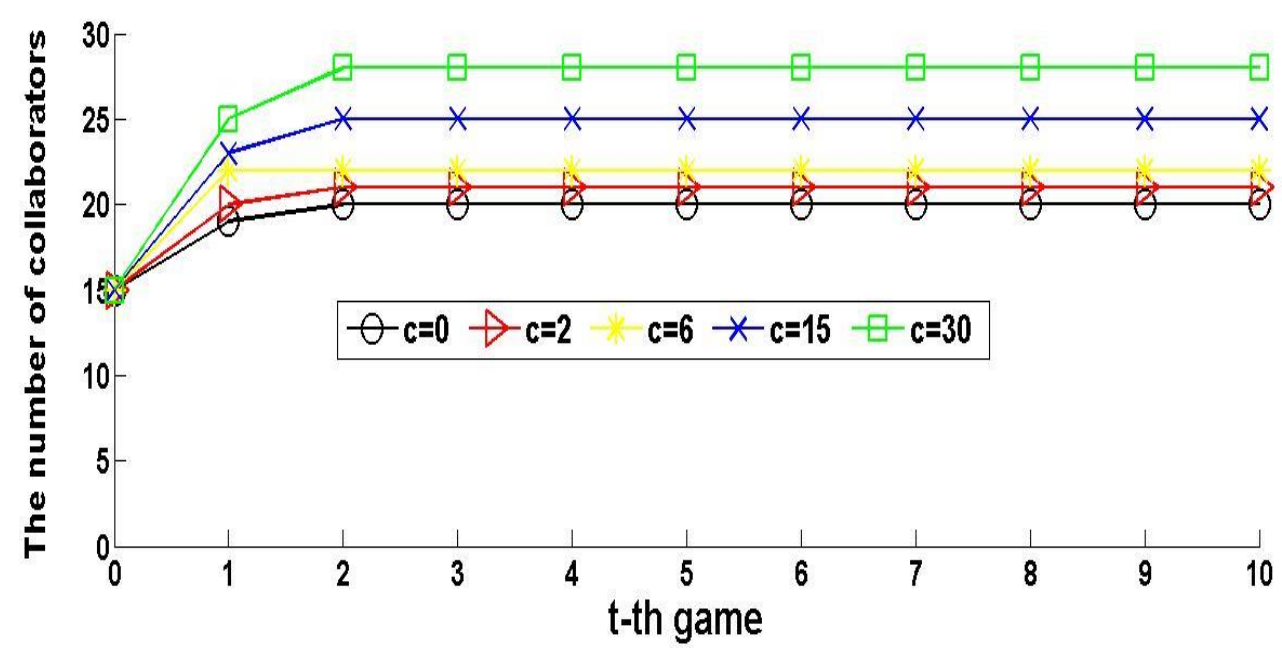

Figure 5. Influence of different initial input costs on the number of collaborators in the blue carbon cooperative network game of the MSR.

In Figure 5, other variables remained unchanged, the value of c kept increasing, and the number of players choosing cooperation also increased, which means the initial investment cost of each game $c$ is positively correlated with the number of partners choosing blue carbon cooperation in the network. When c equals to 0 , the number of collaborators reached 20 during the first two games; when the value of $\mathrm{c}$ was 2, the number of collaborators increases from the initial state of the first game to 20, and reaches 21 and stabilizes in the second game; when the value of $c$ was 6 , the number of cooperators reaches a stable value of 22 in the first game, and the average number of cooperators increases. When the value of $\mathrm{c}$ was 15 , the number of cooperators in the first three games gradually increases to 25 , and stabilizes at this value; and when the value of $\mathrm{c}$ is 30 , the number of node countries that choose the cooperation strategy remains stable at 28 .

It can be seen that the initial investment cost had a positive impact on the cooperation. The initial input cost was mainly used for the cultivation of coastal plants in the blue carbon sink enhancement activities. The greater the initial input cost was, the larger the planting area was, and the more carbon sequestration amount of coastal plants was, so that the carbon sink benefits were increased and the cooperation intention of participants will be strengthened. In other words, increasing the standard of initial input cost can help countries in the network choose cooperative strategies, participate in blue carbon production, reduce carbon emission, and conduct environmental governance. When the initial input cost increases to a certain extent, the number of countries that choose the cooperation strategy will not increase any more, which means that, at this time, the incremental benefits brought by the increased cost cannot attract countries to choose cooperation, and countries in the network tend to pay attention to the impact of other variables. 
4.2.3. The Impact of the Annual Fixed Input Cost of the Game on the Blue Carbon Cooperation along the MSR

Assume that the annual income discount rate is 0.12 , the initial input cost of the game is 16 , the cost-return coefficient was 1 , the profitable period for each game is 10 , and the cost subsidy rate given by the neighbor is 0.06 ; the carbon tax rate for carbon-containing commodities between trade-linked countries was 0.2 , and the carbon reduction rate for commodities when choosing a cooperation strategy was 0.1 . The noise perceived by the participants from other country's choices was $\mu=0.1$, the noise from the participants' own choice was $\gamma=0.2$, the perceived ratio of non-nash equalizers was $\varepsilon=0.1$, and the probability of selection for the two strategies obeyed the uniform distribution $P_{0}=0.5$, which means the initial number of collaborators was 15 . The game income matrix of the MSR blue carbon environmental protection cooperation node $i, j$ is affected by the fixed input cost $d$ per year after each game is selected, and the simulation results were obtained when $d$ was 0,2 , and 5, respectively, as shown in Figure 6 below:

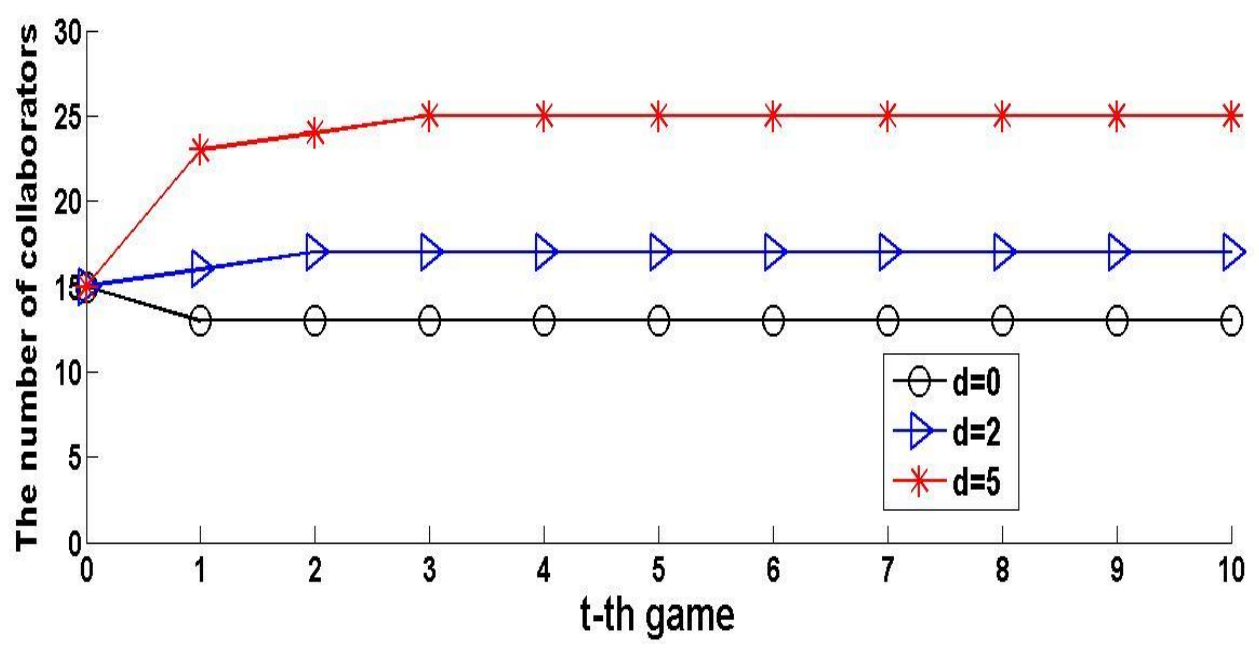

Figure 6. Influence of different annual fixed input costs on the number of collaborators in the blue carbon cooperative network game of the MSR.

It can be seen from the simulation results that when other parameters are fixed, the number of game partners increases as the value of $d$ increases. When the fixed cooperation cost input was 0 per year, the number of partners decreased from the initial state to 13; when $d$ took the value of 2 , the number of partners reached stability in the second game, and after that, the number of partners remained at 17; when the value of $d$ was 5 , the number of partners increased from 15 to 25 .

It can be seen from the analysis that the fixed input cost had a positive impact on cooperation every year. The larger the fixed input cost $d$, the more obvious the network participants' cooperation tendency, and the more willing that the node countries are to reduce carbon emissions collaboratively. The result shows that countries with better economic development should promote the cooperation of the MSR. It is necessary to assist the countries along the route to increase the production input and output of the blue carbon system, and enhance cooperation and development.

4.2.4. The Impact of the Discount Rate of Income of the Game on the Blue Carbon Cooperation along the MSR

Assume that the initial input cost of the game is 12 , the fixed input cost is 0.5 per year, the cost-return coefficient was 5 , the revenue period available for each game was 10 , and the cost subsidy rate given by the neighbor was 0.06 . The carbon tax rate for carbon-containing commodities between trade-linked countries along the MSR was 0.2 , and the carbon reduction rate for commodities when choosing a cooperation strategy is 0.1 . The noise perceived by the participants from other country's choices was 
$\mu=0.1$, the noise from the participants' own choice was $\gamma=0.2$, the perceived ratio of non-nash equalizers was $\varepsilon=0.1$, and the initial number of collaborators was 15 . We changed the value of the return rate, $r$, and observed the impact of the discount rate on the number of partners. The discount rates, $r$, are $0.06,0.2,0.3$, and 0.5, respectively. The simulation results obtained are shown in Figure 7 :

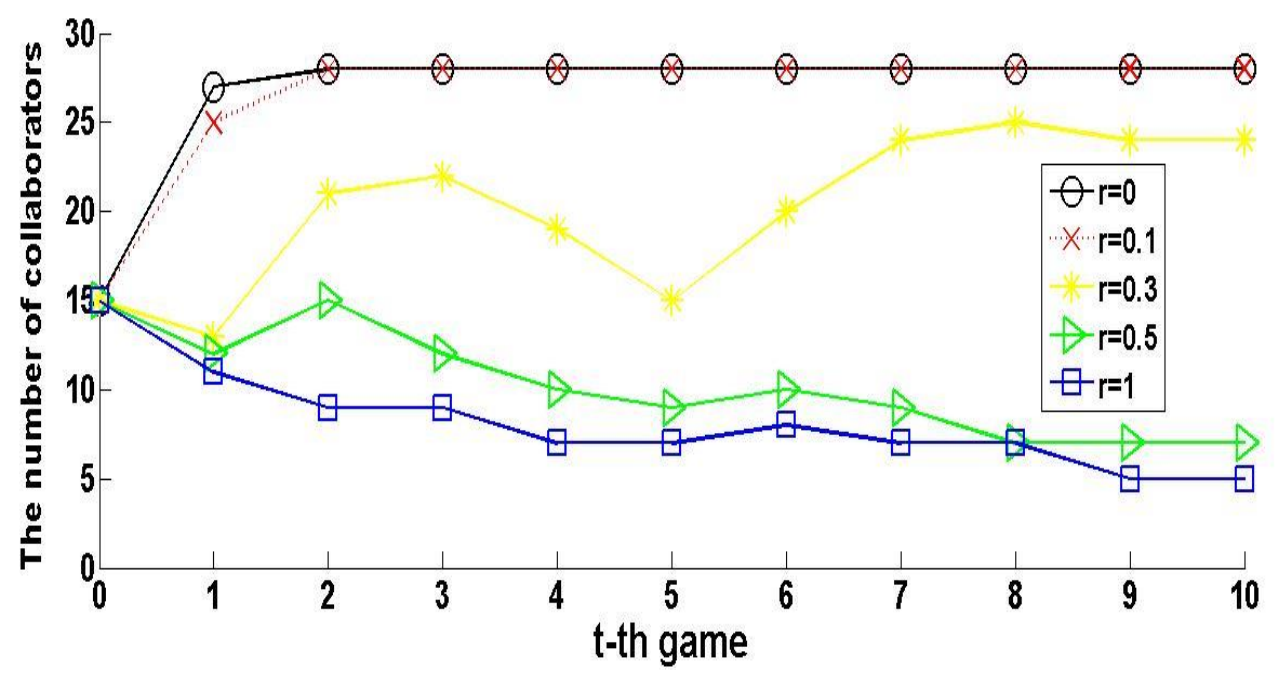

Figure 7. Influence of different discount rates of income on the number of collaborators in the blue carbon cooperative network game of the MSR.

In Figure 7, when the discount rate of return is 0.06 , the number of partners in the first game increased rapidly to 25 , and the second game started to stabilize at 28 . When the discount rate was 0 , the number of collaborators stays at 28; when the discount rate was 0.1 , the curve starting overlap with the curve at 28 when $r=0$ after two games; when the discount rate was 0.3 , the number of partners fluctuates greatly and finally hovers at 23 and 24 ; when the discount rate was 0.5 , the number of partners starts to decline from the initial state of cooperation, and the number of partners finally stabilizes at 7; when the discount rate was 0.5 , the numbers of collaborators finally reaches 5 .

It can be seen from the results that the smaller the discount rate, the more the countries in each node tend to choose the cooperation strategy. Discount rate is, in fact, considering the interest rate and inflation in the future. The present value of the income obtained after discounting can better measure the amount of income generated by the choice of cooperation strategy. When the discount rate is too high, it means the major part of the revenue is due to the interest rate and inflation, and the benefits of participating in the blue carbon environmental protection governance are not significant. Therefore, when future earnings are expected, excessive interest rates and inflation rates will reduce the enthusiasm of each node country to choose a cooperation strategy, which means that the greater the discount rate, the smaller the number of game partners.

4.2.5. The Impact of the Cost-Return Coefficient of the Game on the Blue Carbon Cooperation along the MSR

Assume that the annual income has a discount rate of 0.12 , and the initial input cost is 16 ; then the annual input cost was 0.5 . The profitable period for each game was 10 , and the cost subsidy rate from neighbors is 0.06 . The carbon tax rate of the commodity is 0.2 , and the carbon reduction rate of the commodity when the cooperation strategy was 0.05 . The noise perceived by the participants from other country's choices was $\mu=0.1$, the noise from the participants' own choice was $\gamma=0.2$, the perceived ratio of non-nash equalizers was $\varepsilon=0.1$, and the probability of selection for the two strategies obeys the uniform distribution $P_{0}=0.5$. Take different values for the cost-reward coefficient $\lambda$ and observe its impact on the number of partners. The simulation results obtained when the cost-reward coefficient $\lambda$ are $0,1.5,5,15$ and 20, respectively, are shown in Figure 8: 


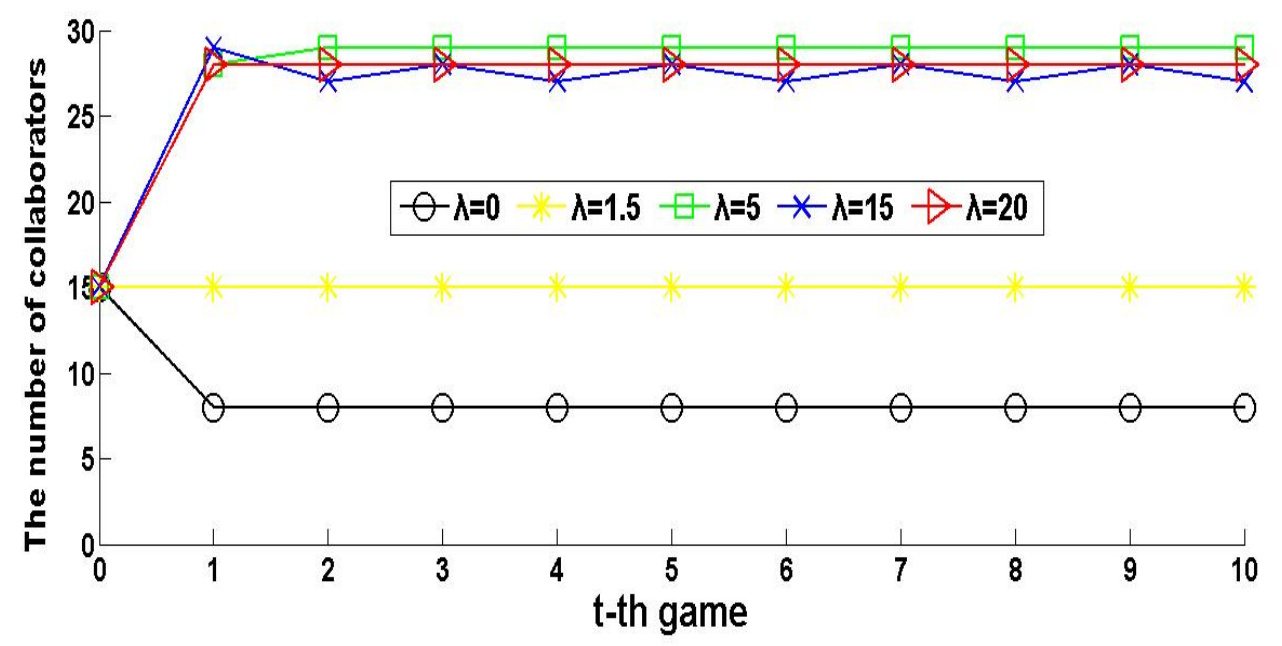

Figure 8. Influence of different cost-return coefficients on the number of collaborators in the blue carbon cooperative network game of the MSR.

As can be seen from the simulation results, when other variables remain unchanged, the average number of partners increases with the return coefficient gradually increases. When $\lambda=0$, the number of participants who choose cooperation is lower than the initial number, decreasing from the initial 15 to 8 ; when $\lambda=1.5$, the number of partners remains stable in the initial state of 15 ; when $\lambda$ was 5 , the number of cooperators increased in the first two games: in the first game it was 28 , and in the second game it started to stabilize at 29 ; when $\lambda$ was 15 , the number of collaborators fluctuated between 27 and 28 from the second game; and when $\lambda$ was 20 , the number of partners is fixed at 28 from the first game. At the same time, compared with the initial state, with the increase of the cost-return coefficient, the game curve moves from downward to upward, indicating that the return coefficient has an inhibitory effect on the cooperation intention of all node countries when it is lower than a certain value.

It can be seen that the blue carbon cooperation behaviors of the MSR countries are sensitive to the cost-return coefficient. When the cost-return coefficient is too small, the countries in the network have little interest in cooperation after the comparison of benefits and costs. The greater the cost-return coefficient, the more willing network participants are to choose cooperative strategies. However, when the cost-return coefficient reaches a certain value, the number of collaborators begins to fluctuate within a small range.

4.2.6. The Impact of Subsidy Rates Given by Neighboring Countries of the Game on the Blue Carbon Cooperation along the MSR

Assume that the annual return rate is 0.12 , the initial input cost was 16 , and then the annual input cost was 0.5 ; the cost coefficient of returns was 5 , the profitable period for each game was 10 , the carbon tax rate for carbon-containing commodities was 0.2 , and the carbon reduction rate for commodities when choosing a cooperation strategy was 0.1 . The noise perceived by the participants from other country's choices was $\mu=0.1$, the noise from the participants' own choice was $\gamma=0.2$, the perceived ratio of non-nash equalizers was $\varepsilon=0.1$, and the probability of selection for the two strategies obeys the uniform distribution $P_{0}=0.5$, which means the initial number of collaborators was 15 . At the same time, the carbon reduction rates, $v$, were $0,0.005,0.01,0.1,0.5$ and 1 , respectively. Observe the influence of different values on the number of partners. The simulation results are shown in Figure 9: 


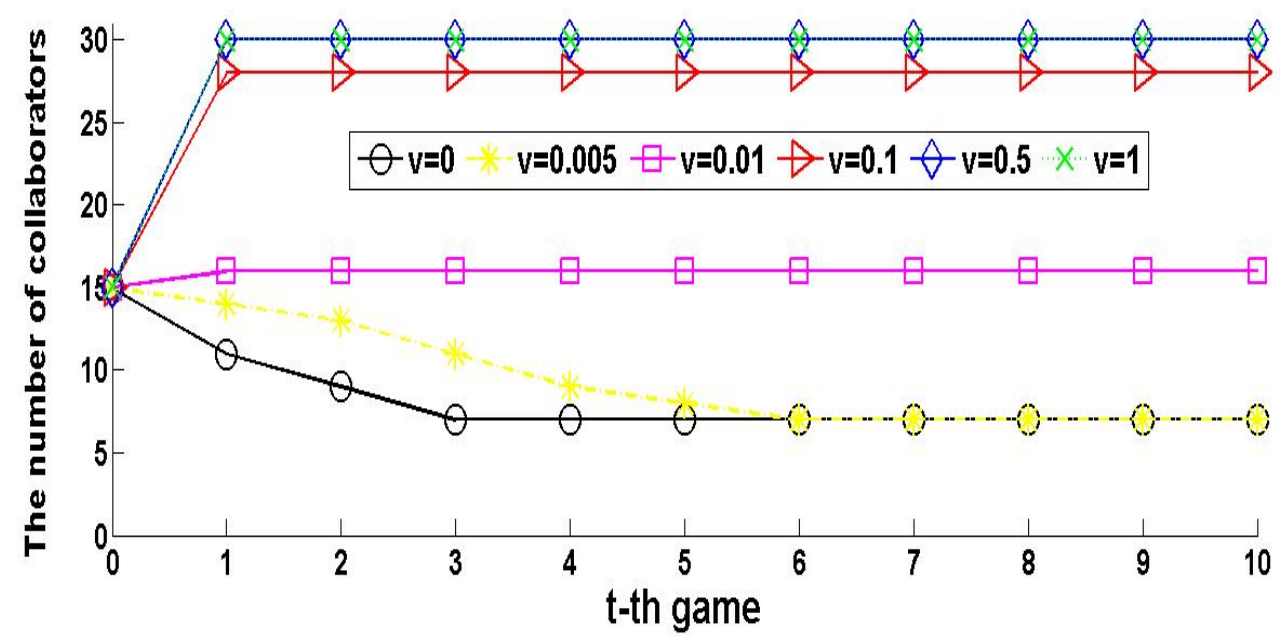

Figure 9. Influence of different subsidy rates on the number of collaborators in the blue carbon cooperative network game of the MSR.

It can be seen from the simulation results that the subsidies provided by neighbors promote the overall cooperation of the blue carbon complex network of the MSR. When other parameters remain unchanged, the neighbor subsidy rate was 0 , and the number of partners starts to decline from the initial state. After three games, the number of collaborators was stable at seven. When the neighbor subsidy rate was 0.005 , it reaches a stable state after six games. At this time, the number of cooperative countries was still seven. When the subsidy rate was 0.01 , the number of partners maintains the state of 16 from the first game. When the subsidy rate of neighbors increased to 0.1 , the number of partners increased from the initial state, and 28 stable cooperative numbers were reached from the first game. When it continued to increase to 0.5 , all countries in the network chose cooperative strategies from the first game; and when the subsidy rate was 1 , the curve coincides with that at 0.5 , where the number of collaborators was 30 . Results indicate that neighbor subsidy has a significant positive impact on the blue carbon cooperation of the MSR, and increasing neighbor subsidy rate can effectively promote network cooperation.

\subsubsection{The Impact of Carbon Tax of the Game on the Blue Carbon Cooperation along the MSR}

Suppose that the discount rate of annual income is 0.12 , the cost subsidy rate given by neighbors was 0.06 , the initial input cost was 10 , and then the annual input cost was 0.5 ; the cost-return coefficient was 3 , the revenue period of each game was 10 , and the carbon content of commodities decreased by 0.1 when the cooperative strategy was selected. The noise perceived by the participants from other country's choices was $\mu=0.1$, the noise from the participants' own choice was $\gamma=0.2$, the perceived ratio of non-nash equalizers was $\varepsilon=0.1$, and the probability of selection for the two strategies obeyed the uniform distribution $P_{0}=0.5$, which means the initial number of collaborators was 15 . Take a different value for the carbon tax rate between countries in a complex network and observe its impact on the number of partners. The simulation results obtained when the carbon tax rates were $0,0.2,0.5$, 0.8 and 1, respectively, are shown in Figure 10: 


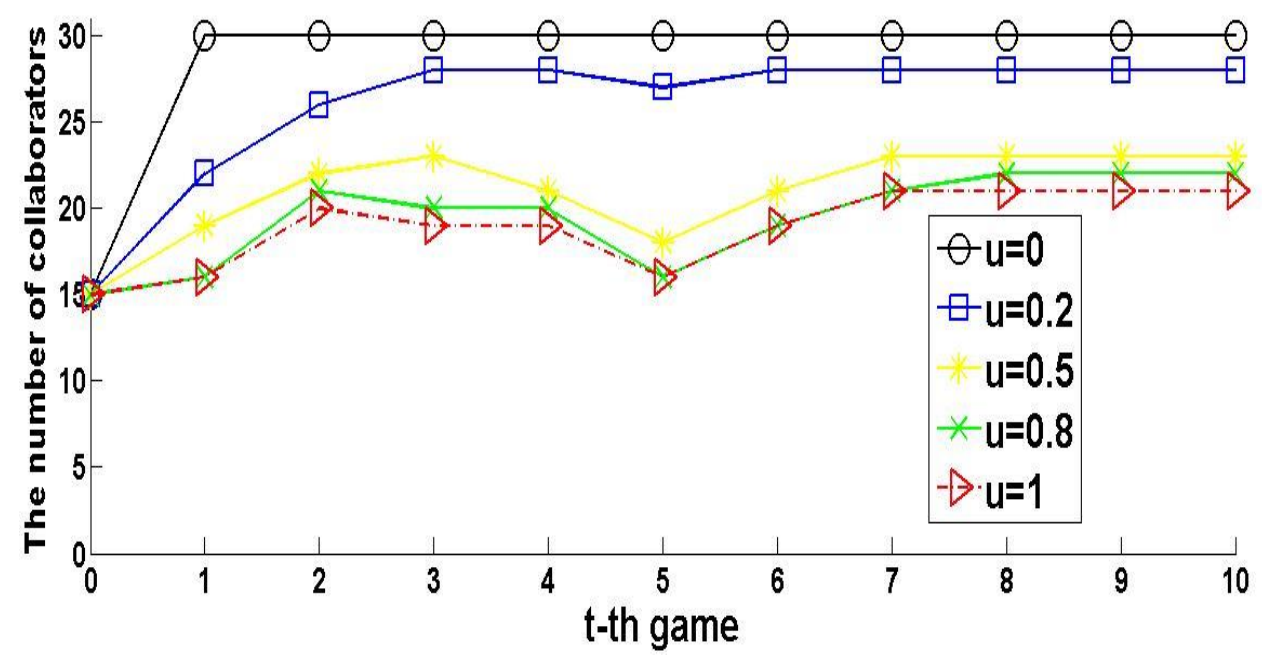

Figure 10. Influence of different carbon tax rates on the number of collaborators in the blue carbon cooperative network game of the MSR.

In Figure 10, other variables are fixed. As the tax rate increased, the curve of the number of partners shifted downward. When the carbon tax rate was 0 , the highest point of the number of partners was 30, which means all the node countries in the network chose the cooperation strategy; when the tax rate was 0.2 , the final stable value of the number of partners changes to 28 ; when the tax rate value was 0.5 , the number of collaborators stabilizes at 23 after seven games; when it gradually increases to 0.8 , the stable value of the curve decreases to 22 ; when it increases to 1 , the curve fluctuates significantly and is fixed at 21 after seven games. It can be seen from the analysis that with the increase of carbon tax rate, the number of countries choosing cooperative strategies in the network decreases.

The simulation results of the carbon tax factor were not consistent with common sense. In general, carbon tax takes the carbon content in the net exports of each node country in the network as the object of collection, which is a kind of punishment for the production of carbon dioxide emission of each country. When a country's net exports are positive, the country needs to pay taxes, which forms expenditure; when net exports are negative, the country receives taxes paid by other countries, which is an income. Some countries along the MSR are in the pre-take-off stage of their economies, with underdeveloped manufacturing industries and negative net exports of carbon-containing commodities. They can benefit from the carbon tax mechanism. However, the industrial economy is an efficient production system. Without the support of an industrial system, economic growth will be impeded, which will lead to other social problems. Thus, some developing countries are willing to pay carbon taxes to develop industries, increase net exports and leapfrog the stage of economic development. Carbon tax has the effect of hindering cooperation under certain conditions because it inhibits the export of a country's goods and impedes the development of goods trade.

4.2.8. The Impact of the Reduction Rate of Carbon-Containing Commodities in the game on the Blue Carbon Cooperation along the MSR

Suppose that the discount rate of annual income is 0.12 , the cost subsidy rate given by neighbors was 0.06 , the initial input cost was 16 , and the annual input cost was 0.5 ; the cost-return coefficient was 5 , the revenue period of each game was 10 , and the carbon tax rate of countries connected by the MSR trade on carbon-containing commodities was 0.2 . The noise perceived by the participants from other country's choices was $\mu=0.1$, the noise from the participants' own choice was $\gamma=0.2$, the perceived ratio of non-nash equalizers was $\varepsilon=0.1$, and the initial number of collaborators is 15 . At the same time, the carbon reduction rate $\beta$ of the selection cooperation strategy were taken as $0,0.1,0.2,0.5$ and 1 , 
respectively. Observe the influence of different values on the number of partners. The simulation results are shown in Figure 11:

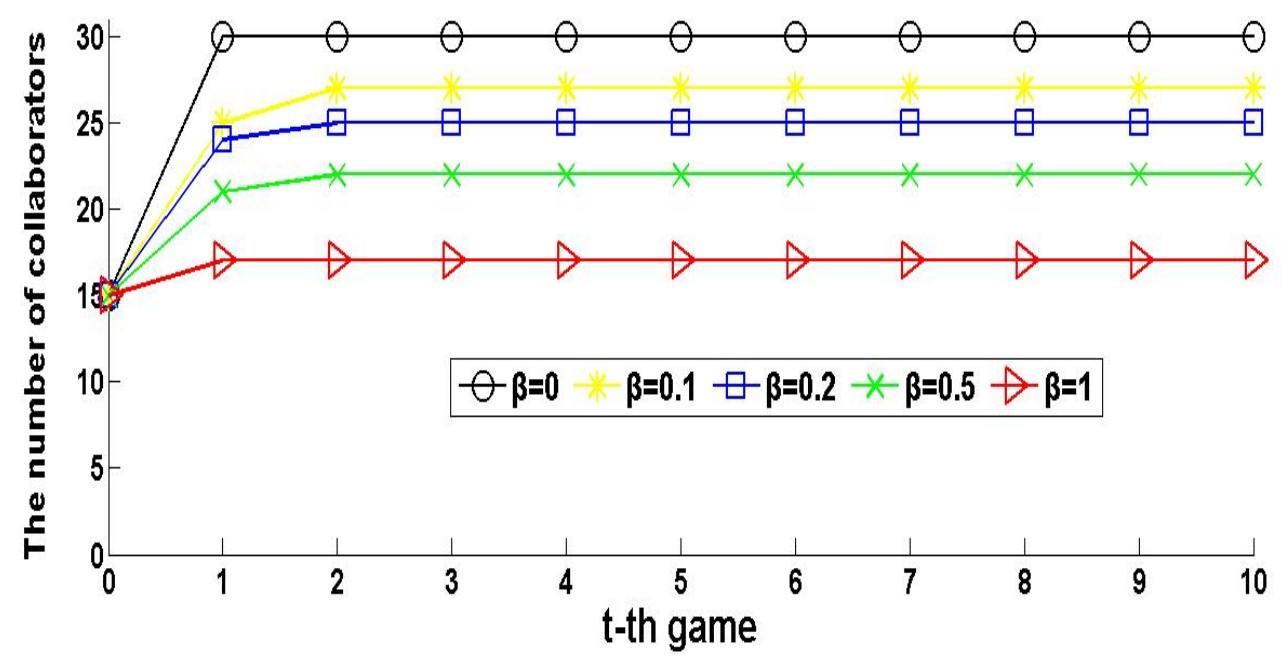

Figure 11. Influence of different reduction rates of carbon-containing commodities on the number of collaborators in the blue carbon cooperative network game of the MSR.

As can be seen from the simulation results, when $\beta=0$, the number of cooperators was the largest, and the value stabilized at 30 from the first game. The number of collaborators decreased as $\beta$ increased from 0 to 1 . When $\beta=0.1$, the stable value of the number of partners was 27 ; when $\beta=0.2$, the number of collaborators decreased to 25 ; when $\beta=0.5$, the number of collaborators stabilized at 22; and when $\beta=1$, the number of collaborators was fixed at 17 .

It can be seen that the reduction rate of commodity carbon content in the selection of cooperation strategy has a negative impact on the strategic selection of countries in the MSR blue carbon cooperation network. When node countries choose cooperation strategies, out of the sense of responsibility of environmental protection, they would reduce the production of the commodities with high carbon content in import and export commodities, which means a decrease of carbon content in commodities. At this point, for countries with negative net export commodity quantity, the base of carbon tax revenue calculation decreases, and other conditions remain unchanged. The greater the $\beta$, the smaller the total revenue, and the more inclined the node countries are to choose not to cooperate.

\section{Discussion and Conclusions}

In this research, we constructed a blue carbon collaboration network along the MSR. By applying a simulation approach, we explored the influence of different factors on the final number of cooperators which include: different types of decision makers, initial input cost, annual fixed input cost, discount rate of income, cost-return coefficient, subsidy rates given by neighboring countries, carbon tax, and the reduction rate of carbon-containing commodities. The theoretical analysis and simulation results of the simulation model can be concluded as follows:

\subsection{Conclusion}

First, the decision-making type of the MSR countries has a certain impact on the blue carbon cooperation of the network. The more decision makers of the equal-choice strategy there are, the easier it is to achieve the blue carbon cooperation of the network; and the greater the number of rational and savvy decision makers, the more unstable the state of achieving all cooperation is and the more likely it is to fluctuate. Our research divided the decision makers into five types that presented various results. When considering the realistic factors, however, the decision-making behavior between countries could 
be even more complex, which makes it difficult to analyze the actual blue carbon cooperation between countries along the MSR.

Second, when considering the cost, whether it is the initial input cost or the fixed input cost, the larger the investment, the greater the gain in a certain range. However, it is worth noting that the benefits appear to be more sensitive to annual fixed input costs, which may be related to subsequent blue carbon management and maintenance efficiency. For the promotion of the blue carbon cooperation, the current technologies related to blue carbon are not mature enough, and excessive investment at the beginning may lead to a waste of capital. Each node country can determine a reasonable initial input value for blue carbon planting, and then invest in the maintenance of the blue carbon ecosystem during its growth period.

Third, investment return coefficient and neighbor subsidy rate have positive effects on blue carbon cooperation along the MSR. In fact, the investment return coefficient is associated with the blue carbon output efficiency of an ecosystem; that is, the higher the output efficiency, the more likely that the relevant countries obtain higher returns, which will further promote the investment in the industrial chain formed by these countries. The spillover effects of blue carbon ecosystem will promote neighbor countries' blue carbon production, and showcase a positive demonstration effect of the cooperation.

Fourth, the results mentioned above that a high carbon tax rate would be detrimental to cooperation have caused us to ponder. Blue carbon production is a sustainable development model which includes three aspects of economic, social and environmental aspects. A carbon tax would inhibit manufacturing exports, while some MSR countries are in the pre-economy and take-off phase and, currently, the constructions taking place in these countries are generating significant blue carbon damage due to the explosion of shipping and the construction of deep-sea ports (Chittagong, Gwadar, etc.). The carbon tax is not conducive to these countries' development of manufacturing, restraining exports, and reducing economic performance. Therefore, some countries will be resistant to the carbon tax system.

Finally, from the results of comprehensive comparative simulation, it can be concluded that the effect of the reward mechanism is better than that of the penalty mechanism. This conclusion is consistent with people's aversion to risk and has pointed out the direction for the design and promotion of the blue carbon cooperation mechanism. In the process of blue carbon cooperation on the MSR, more incentives for investment mechanism design are needed to form a positive expectation of cooperation and to promote cooperation. Of course, in order to curb the "free rider" problem, an appropriate punishment mechanism is also necessary. The carbon tax mechanism should be developed in MSR countries and, when there is a large export deficit of carbon-containing commodities, it will effectively curb the carbon emission behavior of these countries and reduce environmental pollution.

\subsection{Contributions and Limitations}

Our research is among one of the first to apply the quantitative model to study the blue carbon cooperation mechanism of the MSR. The conclusions of the research provide a theoretical basis for the policy regulation and management decision-making of the blue carbon cooperation of the MSR. According to our findings, China's blue carbon cooperation to promote the economic network of the MSR can start from the following aspects: First, increase the investment of blue carbon scientific research funds, to support academic research and develop new technologies to improve the efficiency of blue carbon output, and share and cooperate with the coastal countries on the MSR. This is consistent with the knowledge sharing mentioned in the previous literature, like in the PEMSEA report [12], and our results highlight the benefits of sharing blue carbon production technologies.

Second, the establishment of a blue carbon investment finance organization can be advocated, through which the financing of blue carbon can be carried out to provide financial support and guarantee for the blue carbon investment of countries along the MSR. The national governments along the MSR can guide through policies to increase the credit inclination of financial credit for the development of the blue carbon industry. Financial institutions can increase financial support for 
blue carbon industry research and development (RD) companies based on environmental quality assessment elements and green credit assessment systems, and form strong blue carbon financial support. For example, financial support can be provided for investing in blue carbon ecosystems or blue carbon protection. Such financial support will bring economic benefits, and with the support of the technology, there will be a considerable return, thus promoting the development of the blue carbon economy.

In addition, we propose the establishment of a blue carbon trading market, using the market mechanism to subsidize those countries engaged in blue carbon production, and improve the initiative of blue carbon production of MSR countries. However, the establishment of the blue carbon trading market must first establish a systematic market trading system with clear trading subject rules, trading method rules and pricing rules, and then the trading market can be improved gradually. This also requires a long exploration period.

We also suggest the establishment of the carbon tax alliance along the MSR for countries to reach an agreement on carbon tax through negotiation, and use the carbon tax mechanism to curb carbon emissions and promote energy conservation and emission reduction. Of course, this action needs to take the particularities of developing countries along MSR into account.

Our innovative contributions of the research are as follows: first, the decision structure model is introduced into the research of the blue carbon cooperation mechanism, and the game model is used to study the specific implementation of the blue carbon cooperation along the MSR, which is like reaching a common governance agreement or forming a governance alliance in the MSR counties. To some extent, this answers the Q1; "how to achieve the blue carbon international cooperation?". Considering the impact of decision types on blue carbon cooperation provides a reference for establishing a more realistic cooperation model; the discounted present value of future income and other factors are also introduced into the blue carbon investment returns to make the simulation conclusion more consistent with the actual decision-making process. At the same time, the results obtained by simulating the game model using Matlab software answers the question "What is the impact of factors in the implementation process on blue carbon cooperation?".

In addition, the topic of blue carbon cooperation was combined with the MSR for cross-research, which expand the scope of cooperation and provide a new adhesive for the community construction of the MSR.

Nevertheless, this research has the following limitations: the assumptions of the model are still idealistic, the requirements are too strict, and there is a gap between the randomness and irrationality of the cooperation strategy selection of realistic countries. National decision-making is not always rational. It is influenced by many factors such as geopolitical factors, international economic structure, and national security. Under certain conditions, geopolitical and national security factors take precedence over economic development. MSR countries may choose blue carbon non-cooperation strategies due to political factors. In the future research, the latest behavioral economic theory can be introduced into the model construction to increase the geopolitical and national security factors and relax the variable constraints. This would make the model more realistic and the corresponding governance of carbon emissions more feasible.

Author Contributions: C.Z. and X.X. built models and performed the numerical simulation. Y.G., H.F. and H.C. advised in the process of paper writing and revised the whole paper. All authors contributed to the writing, and have read and approved the final manuscript.

Funding: This research was funded by National Natural Science Foundation of China, grant number 61473053.

Conflicts of Interest: The authors declare no conflict of interest. 


\section{References}

1. Alongi, D. Carbon Cycling and Storage in Mangrove Forests. Annu. Rev. Mar. Sci. 2014, 6, $195-219$. [CrossRef] [PubMed]

2. Gradskov, D.A.; Kazarinov, I.A.; Ignatov, V.V. Bioelectrochemical Oxidation of Glucose with Bacteria Escherichia coli. Russ. J. Electrochem. 2001, 37, 1216-1219. [CrossRef]

3. Tang, J.; Ye, S.; Chen, X.; Yang, H.; Sun, X.; Wang, F.; Wen, Q.; Chen, S. Coastal blue carbon: Concept, study method, and the application to ecological restoration. Sci. China Earth Sci. 2018, 61, 637-646. [CrossRef]

4. Duarte, C.; Borum, J.; Short, F.; Walker, D. Seagrass ecosystems: Their global status and prospects. Aquat. Ecosyst. 2008, 281-294.

5. Silliman, B.R.; Grosholz, E.; Bertness, M.D. Human Impacts on Salt Marshes; University of California Press: Berkeley, CA, USA, 2009; pp. 234-256.

6. Woodroffe, C.D. Response of tide-dominated mangrove shorelines in Northern Australia to anticipated sea-level rise. Earth Surf. Process. Landf. 2010, 20, 65-85. [CrossRef]

7. Björk, M.; Short, F.; McLeod, E.; Beer, S. Managing Seagrasses for Resilience to Climate Change; IUCN: Gland, Switzerland, 2008.

8. Jiao, N.Z. Marine carbon sequestration and carbon storage-And the important role of micro-organisms. Sci. Sin. Terrae 2012, 42, 1473-1486. (In Chinese)

9. Lu, W.F.; Luo, Y.W.; Yan, X.H.; Jiang, Y.W. Modeling the contribution of the microbial carbon pump to carbon sequestration in the South China Sea. Sci. China Earth Sci. 2018, 61, 1594. [CrossRef]

10. Shen, J.S.; Liang, R.F. Study on the blue carbon sink pricing of marine ranch. Resour. Sci. 2018, 40, $1812-1821$.

11. Dong, S.C.; Huang, Y.B.; Li, Z.H.; Shi, G.; Mao, Q.; Li, J.; Yu, H. Economic Development Patterns and Regional Economic Integration Modes for the Silk Road Economic Zone. Resour. Sci. 2014, 36, 2451-2458. (In Chinese)

12. Crooks, S.; von Unger, M.; Schile, L.; Allen, C.; Whisnant, R. Understanding Strategic Coastal Blue Carbon Opportunities in the Seas of East Asia; PEMSEA: Quezon City, Philippines, 2017; pp. 1-43.

13. Zhang, C.; Wang, M. Study on the Blue Carbon Cooperation Mechanism of the Countries along the Maritime Silk Road. Econ. Geogr. 2018, 12, 25-31, 59. (In Chinese)

14. Thomas, S. Blue carbon: Knowledge gaps, critical issues, and novel approaches. Ecol. Econ. 2014, 107, $22-38$. [CrossRef]

15. Samantha Sifleet, L.P.; Brian, C.M. State of the Science on Coastal Blue Carbon: A Summary for Policy Makers; Duke University: Durham, NC, USA, 2011; pp. 4-21.

16. Nellemann, C.; Corcoran, E.; Duarte, C.M.; Valdés, L.; De Young, C.; Fonseca, L.; Grimsditch, G. Blue Carbon: A UNEP Rapid Response Assessment; United Nations Environment Program; GRID-Arendal: Arendal, Norway, 2009.

17. Garrard, S.L.; Beaumont, N.J. The effect of ocean acidification on carbon storage and sequestration in seagrass beds; a global and UK context. Mar. Pollut. Bull. 2014, 86, 138-146. [CrossRef]

18. Donato, D.C.; Kauffman, J.B.; Murdiyarso, D.; Kurnianto, S.; Stidham, M.; Kanninen, M. Mangroves among the most carbon-rich forests in the tropics. Nat. Geosci. 2011, 4, 293-297. [CrossRef]

19. Duarte, C.M.; Losada, I.J.; Hendriks, I.E.; Mazarrasa, I.; Marbà, N. The role of coastal plant communities for climate change mitigation and adaptation. Nat. Clim. Chang. 2013, 3, 961-968. [CrossRef]

20. Waycott, M.; Duarte, C.M.; Carruthers, T.J.; Orth, R.J.; Dennison, W.C.; Olyarnik, S.; Calladine, A.; Fourqurean, J.W.; Heck, K.L.; Hughes, A.R.; et al. Accelerating loss of seagrasses across the globe threatens coastal ecosystems. Proc. Natl. Acad. Sci. USA 2009, 106, 12377-12381. [CrossRef]

21. Kennedy, H.; Beggins, J.; Duarte, C.M.; Fourqurean, J.W.; Holmer, M.; Marbà, N.; Middelburg, J.J. Seagrass sediments as a global carbon sink: Isotopic constraints. Glob. Biogeochem. Cycles 2010, 24, 6696-6705. [CrossRef]

22. Pendleton, L.; Donato, D.; Murray, B.; Crooks, S.; Aaron Jenkins, W.; Sifleet, S.; Craft, C.; Fourqurean, J.W.; Kauffman, J.B.; Marbà, N.; et al. Estimating Global “Blue Carbon" Emissions from Conversion and Degradation of Vegetated Coastal Ecosystems. PLoS ONE 2012, 7, e43542. [CrossRef]

23. Sanders, C.J.; Maher, D.T.; Tait, D.R.; Williams, D.; Holloway, C.; Sippo, J.Z.; Santos, I.R. Are global mangrove carbon stocks driven by rainfall? J. Geophys. Res. Biogeosci. 2016, 121, 2600-2609. [CrossRef]

24. Li, Y.; Qiu, J.; Li, Z.; Li, Y. Assessment of Blue Carbon Storage Loss in Coastal Wetlands under Rapid Reclamation. Sustainability 2018, 10, 2818. [CrossRef] 
25. Lovelock, C.E.; Atwood, T.; Baldock, J.; Duarte, C.M.; Hickey, S.; Lavery, P.S.; Masque, P.; Macreadie, P.I.; Ricart, A.M.; Serrano, O.; et al. Assessing the risk of carbon dioxide emissions from blue carbon ecosystems. Front. Ecol. Environ. 2017, 15, 257-265. [CrossRef]

26. Crooks, S.; Herr, D.; Tamelander, J.; Laffoley, D.; Vandever, J. Mitigating Climate Change through Restoration and Management of Coastal Wetlands and Near-Shore Marine Ecosystems: Challenges and Opportunities; World Bank: Washington, DC, USA, 2011; pp. 7-29.

27. Vierros, M. Communities and blue carbon: The role of traditional management systems in providing benefits for carbon storage, biodiversity conservation and livelihoods. Clim. Chang. 2017, 140, 89-100. [CrossRef]

28. Mou, N.; Liu, C.; Zhang, L.; Fu, X.; Xie, Y.; Li, Y.; Peng, P. Spatial Pattern and Regional Relevance Analysis of the Maritime Silk Road Shipping Network. Sustainability 2018, 10, 977. [CrossRef]

29. Kauffman, J.B.; Heider, C.; Cole, T.G.; Dwire, K.A.; Donato, D.C. Ecosystem Carbon Stocks of Micronesian Mangrove Forests. Wetlands 2011, 31, 343-352. [CrossRef]

30. Pan, Y.; Birdsey, R.A.; Fang, J.; Houghton, R.; Kauppi, P.E.; Kurz, W.A.; Phillips, O.L.; Shvidenko, A.; Lewis, S.L.; Canadell, J.G.; et al. A Large and Persistent Carbon Sink in the World's Forests. Science 2011, 333, 988-993. [CrossRef]

31. Fourqurean, J.W.; Duarte, C.M.; Kennedy, H.; Marbà, N.; Holmer, M.; Mateo, M.A.; Apostolaki, E.T.; Kendrick, G.A.; Krause-Jensen, D.; McGlathery, K.J.; et al. Seagrass ecosystems as a globally significant carbon stock. Nat. Geosci. 2012, 5, 505-509. [CrossRef]

32. Van der Werf, G.R.; Morton, D.C.; DeFries, R.S.; Olivier, J.G.; Kasibhatla, P.S.; Jackson, R.B.; Collatz, G.J.; Randerson, J.T. $\mathrm{CO}_{2}$ emissions from forest loss. Nat. Geosci. 2009, 2, 737-738. [CrossRef]

33. Hamilton, S.E.; Casey, D. Creation of a high spatio-temporal resolution global database of continuous mangrove forest cover for the 21st century (CGMFC-21). Glob. Ecol. Biogeogr. 2016, 6, 729-738. [CrossRef]

34. Wang, C.R. Research on the development of blue carbon in Guangdong province under the background of the 21st century maritime silk road. Ocean. Dev. Manag. 2017, 34, 39-43. (In Chinese)

35. Fan, H.M.; Li, X.X.; Liu, Y.Y.; Mu, X.W.; Zhao, C.P. Simulation Research on Evolutionary Games of the Arctic Environmental Governance Response Complex Network. Manag. Rev. 2017, 2, 26-34. (In Chinese)

36. Xie, F.J. Cooperative incentives for the evolution of game behavior on complex networks. J. Shanghai Jiaotong Univ. 2015, 49, 1256-1262. (In Chinese)

37. Friedman, D. Evolutionary Economics Goes Mainstream: A Review of the Theory of Learning in Games. J. Evol. Econ. 1998, 4, 423-432. [CrossRef]

38. Shakarian, P.; Roos, P.; Johnson, A.N. A Review of Evolutionary Graph Theory with Applications to Game Theory. Biosystems 2012, 2, 66-80. [CrossRef]

39. Vaidyanathan, G. 'Blue carbon' plan takes shape. Nature 2011, 20, 60-62. [CrossRef]

40. Simon, H.A. Administrative Behavior: A Study of Decision-Making Processes in Administrative Organization; Macmillan Co.: New York, NY, USA, 1947; pp. 187-189.

41. Stahl, D.O.; Wilson, P.W. On Players' Models of Other Players: Theory and Experimental Evidence. Games Econ. Behav. 1995, 10, 218-254. [CrossRef]

42. Costa-Gomes, M.; Crawford, V.P.; Broseta, B. Cognition and Behavior in Normal-Form Games: An Experimental Study. Econometrica 2001, 69, 1193-1235. [CrossRef]

43. Wang, Z.; Szolnoki, A.; Perc, M. Evolution of public cooperation on interdependent networks: The impact of biased utility functions. Soc. Sci. Electron. Publ. 2012, 97, 48001. [CrossRef]

44. Ahmad, N. A Framework for Estimating Carbon Dioxide Emissions Embodied in International Trade of Goods. In OECD, Measuring Sustainable Development: Integrated Economic, Environmental and Social Frameworks; OCED Publishing: Paris, France, 2004.

45. Wu, B.; Huang, W.; Liu, P. Carbon Reduction Strategies Based on an NW Small-World Network with a Progressive Carbon Tax. Sustainability 2017, 9, 1747. [CrossRef]

(C) 2019 by the authors. Licensee MDPI, Basel, Switzerland. This article is an open access article distributed under the terms and conditions of the Creative Commons Attribution (CC BY) license (http://creativecommons.org/licenses/by/4.0/). 